\title{
Baicalin alleviates bleomycin-induced pulmonary fibrosis and fibroblast proliferation in rats via the PI3K/AKT signaling pathway
}

\author{
HONG ZHAO ${ }^{1,2}, \mathrm{CHUNDI} \mathrm{LI}^{2}, \mathrm{LINA} \mathrm{LI}^{2}, \mathrm{JUNYING} \mathrm{LIU}^{2}$, YINGHUI GAO ${ }^{2}, \mathrm{KUN} \mathrm{MU}^{2}$, \\ DONGHE CHEN ${ }^{2}$, AIPING LU ${ }^{2}$, YUANYUAN REN ${ }^{2}$ and ZHENHUA LI ${ }^{1}$
}

\author{
${ }^{1}$ Department of Respiratory Medicine, First Affiliated Hospital of China Medical University, Shenyang, Liaoning 110001; \\ ${ }^{2}$ Department of Respiratory Medicine, Fifth Affiliated Hospital of Harbin Medical University, Daqing, \\ Heilongjiang 163316, P.R. China
}

Received March 23, 2019; Accepted January 13, 2020

DOI: $10.3892 / \mathrm{mmr} .2020 .11046$

\begin{abstract}
Baicalin is an important flavonoid compound THAT is isolated from the Scutellaria baicalensis Georgi Chinese herb and plays a critical role in anti-oxidative, anti-inflammatory, anti-infection and anti-tumor functions. Although baicalin can suppress the proliferation of tumor cells, the underlying mechanisms of baicalin in bleomycin (BLM)-induced pulmonary fibrosis remain to be elucidated. Thus, the aim of the present study was to determine the role of baicalin in pulmonary fibrosis and fibroblast proliferation in rats. Hematoxylin and eosin (H\&E) and Masson staining were used to measure the morphology of pulmonary fibrosis, ELIASA kits were used to test the ROS and inflammation, and western blotting and TUNEL were performed to study the apoptosis proteins. In vitro, MTT assay, flow cytometry, western blotting and immunofluorescence were performed to investigate the effects of baicalin on proliferation of fibroblasts. The most significantly fibrotic changes were identified in the lungs of model rats at day 28 . Baicalin $(50 \mathrm{mg} / \mathrm{kg})$ attenuated the degree of pulmonary fibrosis, and the hydroxyproline content of the lung tissues was decreased in the baicalin group, compared with the BLM group. Further investigation revealed that baicalin significantly increased glutathione peroxidase (GSH-px), total-superoxide dismutase (T-SOD) and glutathione (GSH) levels, whilst decreasing that of serum malondialdehyde (MDA). TUNEL-positive cells were significantly decreased in rats treated with baicalin group, compared with the model group. Furthermore, it was found that BLM promoted fibroblasts viability in a dose-dependent manner in vivo, which was
\end{abstract}

Correspondence to: Dr Zhenhua Li, Department of Respiratory Medicine, First Affiliated Hospital of China Medical University, 155 Nanjing North Street, Shenyang, Liaoning 110001, P.R. China E-mail: lzzhh2018@126.com

Key words: baicalin, bleomycin, pulmonary fibrosis, oxidant stress, apoptosis, fibroblast restricted following treatment with different concentrations of baicalin. Moreover, BLM promoted the expression levels of cyclin A, D and E, proliferating cell nuclear antigen, phosphorylated (p)-AKT and p-calcium/calmodulin-dependent protein kinase type. BLM also promoted the transition of cells from the $G_{0} / G_{1}$ phase to the $G_{2} / M$ and $S$ phases, and increased the intracellular $\mathrm{Ca}^{2+}$ concentration, which was subsequently suppressed by baicalin. Collectively, the results of the present study suggested that baicalin exerted a suppressive effect on BLM-induced pulmonary fibrosis and fibroblast proliferation.

\section{Introduction}

Idiopathic pulmonary fibrosis (IPF) is a severe and lethal interstitial lung disease, which is characterized by progressive dyspnea and distorted lung function (1). The incidence of IPF gradually increases with age, and primarily occurs in individuals between $60-70$ years $(2,3)$. A study from the United States estimated that the prevalence rate of IPF varied from 14-43 per 100,000 persons (4). However, despite widespread efforts, the etiology and pathogenesis of the disease remain unclear, and effective treatments with limited side effects are urgently required. Currently, novel treatment strategies should aim to combine multiple therapeutic targets to prevent the pathogenesis of IPF $(5,6)$.

Due to its complexity, the pathogenic mechanism of IPF are not fully understood. The underlying mechanisms of IPF involve multiple pathways, such as the inflammatory response, epithelial-mesenchymal transition (EMT), apoptosis, oxidative stress (7-9), and developmental processes, which leading to alveolar epithelial cell injury and fibroblast proliferation that consequently leads to excessive deposition of extracellular collagen (10). It has been reported that inflammatory cell accumulation, pro-inflammatory cytokine release, including interleukin-6, tumor necrosis factor- $\alpha$ and transforming growth factor- $\beta$, and oxidative stress disorder exacerbate lung injury in bleomycin-induced pulmonary fibrosis (11). The primary pathological features of pulmonary fibrosis are characterized by the damage and apoptosis of pulmonary tissues, excessive proliferation of pulmonary fibroblasts, and 
mass secretion and accumulation of collagen matrix (12). Although glucocorticoids, colchicines and cyclophosphamides are currently used to treat pulmonary fibrosis, their poor curative effect and high incidence of side effects makes them less desirable (13). This highlights the importance of further study into the pathogenesis of pulmonary fibrosis and the examination of multi-target therapeutic drugs, which may offer a new developmental direction for the treatment of IPF. Traditional Chinese medicine compounds are characterized by their multi-targeting nature and low side effects, which allows for the investigation of more suitable drugs for IPF treatment (14).

Baicalin is the biologically active form of the dried roots of Scutellaria baicalensis Georgi, and the major bioactive ingredient of which is flavinoid. The main chemical constituent flavonoid of baicalin has a variety of biological activities, such as including anti-inflammatory (15), antioxidative (16), antithrombotic $(17)$, anti-proliferative $(18,19)$ and regulation of apoptosis (20-22). The multiple functions of baicalin have been well-studied in different fields. Moreover, previous studies have shown that baicalin has protective effects on liver fibrosis induced by $\mathrm{CCl}_{4}$ (23), and it can inhibit the formation of renal fibrosis (24). Baicalin alleviates silica-induced lung inflammation by suppressing IL-6 and IL-23, which reflect Th17 response and lung fibrosis (25). Baicalin also inhibited BLM-induced pulmonary fibrosis by upregulating adenosine $\mathrm{A} 2 \mathrm{a}$ receptor and downregulating transforming growth factor (TGF)- $\beta 1$ and phosphorylated (p)-ERK1/2 expression (26). These results indicate that baicalin is may be a potential treatment for IPF. Thus, it is of great significance to investigate the specific mechanism and signaling pathway via which baicalin inhibits pulmonary fibrosis, as this may be a theoretical basis for the use of baicalin in the treatment of IPF.

$\mathrm{AKT}$ is a serine/threonine protein kinase that is activated by a number of growth factors and cytokines such as TGF- $\beta$ and IL-6, in a phosphatidylinositol-3 kinase (PI3K)-dependent manner (27). The PI3K/AKT signaling pathway is involved in numerous cellular processes, such as cell differentiation, proliferation, apoptosis and angiogenesis (28-30), and is stimulated by the activation of receptor tyrosine kinases, which leads to the translocation of PI3K from the cytoplasm to the plasma membrane (31). Leptin accelerates EMT of human lung carcinoma A549 cell and promotes pulmonary fibrosis by inhibiting autophagy via the PI3K/AKT/mTOR pathway (32). Furthermore, syndecan-2 attenuates radiation-induced pulmonary fibrosis, and inhibits mouse lung fibroblast migration and proliferation by suppressing PI3K/AKT/Rho-associated protein kinase signaling via CD148 (33). Moreover, the $\mathrm{PI} 3 \mathrm{~K} / \mathrm{AKT}$ pathway activates endoplasmic reticulum (ER) stress and influences lung fibroblast proliferation in BLM-induced pulmonary fibrosis (34).

Calcium/calmodulin-dependent kinase II (CaMKII), which is known as a general integrator of $\mathrm{Ca}^{2+}$ signaling, is activated upon binding to $\mathrm{Ca}^{2+} /$ calmodulin $(\mathrm{CaM})$, which subsequently undergoes autophosphorylation (35). Previous studies have revealed that CaM KII is involved in the pathological course of lung diseases via the modulation of intracellular $\mathrm{Ca}^{2+}$ concentrations $(36,37)$. It has also been shown that puerarin stimulates endothelial nitric oxide synthase (eNOS) activation, which is mediated by PI3K/AKT and 5'-AMP-activated protein kinase (AMPK) activation via an ER- and CaMKII-dependent pathway (38). Moreover, prostaglandin $\mathrm{E}_{2}$ was found to interfere with $\mathrm{Ca}^{2+}$ signaling and prevent the activation of AKT and CaMKII in human pulmonary fibroblasts isolated from patients with IPF (39). $\mathrm{Ca}^{2+}$ signaling and calmodulin-dependent protein kinase II $\beta$ and II $\delta$ are also involved in TGF- $\beta$-induced extracellular matrix gene expression in human pulmonary fibroblasts (6). Additionally, insulin stimulates the proliferation of dermal fibroblasts via activated CaMKII, and induces Raf-1 and ERK expression (40). However, the impact of the PI3K/AKT and CaMKII pathways in baicalin-regulated pulmonary fibrosis and pulmonary fibroblast proliferation is not fully understood, Thus the present study aimed to investigate its role and identify its underlying mechanism. It was hypothesized that CaMKII and PI3K/AKT may be involved in the activation of fibroblast proliferation in the pulmonary fibrosis. In the present study, the protective function of adenosine baicalin and lung fibroblast proliferation were investigated in a BLM-induced pulmonary fibrosis model, to determine whether baicalin suppressed lung fibroblasts proliferation via the inhibition of the CaMKII and AKT signaling pathways.

\section{Materials and methods}

Materials. BLM was purchased from Nippon Kayaku Co., Ltd., and dissolved in saline to a final concentration of $5 \mathrm{mg} / \mathrm{ml}$. Baicalin (Sigma-Aldrich; Merck KGaA; purify, $>95 \%$ ) was prepared in physiological saline at a $2 \%$ concentration. The superoxide dismutase (SOD), glutathione peroxidase (GSH-px), malondialdehyde (MDA) and hydroxyproline (Hyp) kits were purchased from the Nanjing Jiancheng Bioengineering Institute. The TUNEL Apoptosis Assay kit was purchased from Roche Diagnostics. Antibodies against Bcl-2 and cyclin A were acquired from Beyotime Institute of Biotechnology. Antibodies against caspase-3, Bax, cyclin D, cyclin E, proliferating cell nuclear antigen (PCNA), phosphorylated (p)-AKT, total (t)-AKT, p-CaMKII, t-CaMKII and $\beta$-actin were acquired from Cell Signaling Technology, Inc. The Cell Cycle and Apoptosis Analysis kit (cat. no. C1052) was purchased from the Beyotime Institute of Biotechnology, and ECL reagents were obtained from GE Healthcare.

Animal model and experimental protocol. Adult female Wistar rats (age, 42-49 days; weight, 160-200 g) used in this study were purchased from the Animal Research Center of Harbin Medical University, which is fully accredited by the Institutional Animal Care and Use Committee. All animals were housed in cages, in a 12:12 h light/dark cycle, the temperature at $24^{\circ} \mathrm{C}$, and humidity of $50-70 \%$, allowed free access to food and water. All experiments were approved by the Animal Care Committee of China Medical University. The animals were randomized into the following four groups ( $n=6 /$ group): i) The sham group; ii) the sham + baicalin group; iii) the BLM group; and iv) the BLM + baicalin group. The pulmonary fibrosis model was prepared as previously reported (41). Briefly, the rats were anesthetized with an intraperitoneal injection of $1 \%$ pentobarbital sodium $(50 \mathrm{mg} / \mathrm{kg})$, and then treated with a single intratracheal instillation of $5 \mathrm{mg} / \mathrm{kg}$ BLM solution. The sham group rats received intratracheal injection 
of an equal volume of the sterilized saline. The following day, $50 \mathrm{mg} / \mathrm{kg}$ baicalin was intraperitoneally administered, which was continued once a day for 28 days, and six animals per group were sacrificed on day 29 . The rats were anesthetized with $1 \%$ pentobarbital sodium $(50 \mathrm{mg} / \mathrm{kg})$, the blood and bronchial alveolar lavage fluid were collected, and the lungs were removed for subsequent experimentation. After sampling, the rats were euthanized by overdose anesthesia. Blood was collected from the abdominal aorta under anesthesia and centrifuged at 2,411 x g for $5 \mathrm{~min}$ at room temperature, and the serum was then stored at $-20^{\circ} \mathrm{C}$ until use. The left lung of each animal was morphologically assessed, the right lung was stored at $-80^{\circ} \mathrm{C}$ and the Hyp content was determined using a commercial assay kit, according to the manufacturer's instructions.

Histology. The left lung was perfused with $4 \%$ paraformaldehyde (PFA) at a pressure of $25 \mathrm{~cm} \mathrm{H}_{2} \mathrm{O}$ via the left principal bronchus at room temperature, and immersed in PFA solution overnight following the tracheal ligation. Subsequently, the lung tissues were embedded in paraffin, and cut into $4-\mu \mathrm{m}$ thick serial sections. Then, 2 min hematoxylin and eosin (H\&E) staining, as well as 8 min Masson staining were performed at room temperature to determine the degree of alveolitis and fibrosis, and the sections were observed by light microscopy (magnification, $\mathrm{x} 10$ ).

Measurement of Hyp content. Frozen lungs ( 100 mg) were cut into fragments and then ground using a glass homogenizer on ice. The Hyp content of the lung tissue was assessed using the Hyp ELISA kit (cat. no. A030-3-1; Nanjing Jiancheng Bioengineering Institute), according to the manufacturer's protocol. Lung tissues were hydrolyzed at $100^{\circ} \mathrm{C}$ for $20 \mathrm{~min}$, and adjusted to a preset $\mathrm{pH}$. The mixture was incubated at $60^{\circ} \mathrm{C}$ for $15 \mathrm{~min}$ and centrifuged at $2,813 \mathrm{x}$ g for $10 \mathrm{~min}$ in room temperature after cooling. The absorbance of each sample at $550 \mathrm{~nm}$ was determined, and the data were calculated as $\mu \mathrm{g}$ Hyp per mg wet lung weight.

Bronchial alveolar lavage fluid $(B A L F)$ cell count. The right lung of each animal was ligated at the hilus, and an 18-gauge catheter was inserted into the trachea and placed in the left main bronchus. BALF was obtained by cannulating the trachea and injecting and retrieving three $3 \mathrm{ml}$ aliquots of sterile saline, the fluid was then centrifuged at 1,205 $\mathrm{x}$ g for $15 \mathrm{~min}$ at $4^{\circ} \mathrm{C}$, and the supernatants were discarded. The cell pellets were resuspended in PBS and the total number of cells was counted using a hemocytometer.

Measurement of MDA content, total-SOD (T-SOD), GSH-px and GSH activities in serum. The enzymatic activities of SOD and GSH, and the MDA content were assessed using different commercial assay kits in accordance with the manufacturer's instructions. The serum content of T-SOD was determined using the T-SOD assay kit (cat. no. A001-1-2; Nanjing Jiancheng Bioengineering Institute), according to the manufacturer's instructions. SOD activity was detected in serum by measuring the ability to inhibit the photochemical reduction of nitro blue tetrazolium (NBT); the optical density was measured at $550 \mathrm{~nm}$ and the data were expressed as $\mu / \mathrm{ml}$.
GSH and GSH-px activity were analyzed using commercial kits per the manufacturer's protocols (GSH, cat. no. A006-2-1; GSH-px, cat. no. A005-1-2; Nanjing Jiancheng Bioengineering Institute), which were based on the consumption of reduced glutathione. Absorbance was determined at $412 \mathrm{~nm}$ and the levels of GSH and GSH-px were defined as $\mu / \mathrm{ml}$.

The serum MDA concentration was detected by measuring the degradation product of thiobarbituric acid at a maximum wavelength of $532 \mathrm{~nm}$, according to the manufacturer's instructions (MDA, cat. no. A003-1-2; Nanjing Jiancheng Bioengineering Institute). Serum samples (100 $\mu \mathrm{l})$ were supplemented with $5 \mathrm{mg} / \mathrm{ml}$ butylated hydroxytoluene to prevent artificial lipid peroxidation. The samples were then centrifuged $\left(1,600 \times \mathrm{g}, 10 \mathrm{~min}, 4^{\circ} \mathrm{C}\right)$ to remove insoluble material, and $100 \mu \mathrm{l}$ supernatants were transferred to a microcentrifuge tube and supplemented with $800 \mu$ l thiobarbituric acid (TBA) to generate an MDA-TBA adduct. To accelerate the process, samples were incubated at $95^{\circ} \mathrm{C}$ for $60 \mathrm{~min}$, placed on an ice bath for $10 \mathrm{~min}$ to inhibit the reaction and centrifuged $\left(1,600 \mathrm{x} \mathrm{g}, 10 \mathrm{~min}, 4^{\circ} \mathrm{C}\right)$. The final product was measured colorimetrically at $532 \mathrm{~nm}$, and the absorbance values were compared to a calibration curve prepared using the MDA standard; data were expressed as $\mathrm{nmol} / \mathrm{ml}$.

Measurement of TGF- $\beta 1$ and TNF- $\alpha$ detection in BALF. The concentrations of TGF- $\beta 1$ and TNF- $\alpha$ in the BALF were determined using the Rat TGF- $\beta 1$ and TNF- $\alpha$ ELISA kits (Rat TGF- $\beta 1$ ELISA kit, cat. no. PT878; Rat TNF- $\alpha$ ELISA kit, cat. no. PT516) according to the manufacturer's instructions. Samples or reference standards $(100 \mu \mathrm{l})$ were added to each well of a microplate precoated with biotinylated antibody $100 \mu \mathrm{l}$ specific to TGF- $\beta 1$ or TNF- $\alpha$ and incubated at room temperature for $60 \mathrm{~min}$. After washing out unbounded proteins, a horseradish peroxidase (HRP)-conjugated polyclonal secondary antibody was added to the wells (100 $\mu \mathrm{l} /$ well) and incubated for $30 \mathrm{~min}$ at room temperature in the dark. After washing with the washing reagent from the kit and $100 \mu$ l developer 3,3',5,5'-Tetramethylbenzidine solution was added at room temperature for $20 \mathrm{~min}$ in the dark, as well as $50 \mu \mathrm{l}$ termination solution, optical density was determined at $450 \mathrm{~nm}$. The results were quantified using the linear regression equation of the standard curve.

TUNEL assay. The detection procedure was performed according to the manufacturer's instructions, but with modifications. Deparaffinized 4- $\mu$ m-thick tissue sections were treated with $20 \mu \mathrm{g} / \mathrm{ml}$ proteinase $\mathrm{K}$ for $15 \mathrm{~min}$ at room temperature. Subsequently, the TUNEL reagent containing dUTP and TdT (Roche Diagnostics) was added to each section, and incubated in a humidified chamber at $37^{\circ} \mathrm{C}$ for $60 \mathrm{~min}$. The sections were rinsed with $\mathrm{PBS}$ and the sections were incubated with $0.3 \%$ converter-peroxidase for $30 \mathrm{~min}$ at $37^{\circ} \mathrm{C}$, then the sections rinsed with PBS prior to the addition of DAB substrate $10 \mathrm{~min}$ at room temperature and color rendering was observed under the microscope for 3-8 min. After the color development with tap water, sections were rinsed for $15 \mathrm{~min}$ and hematoxylin staining was performed for $2 \mathrm{~min}$ at room temperature, and subsequent steps were performed as follows. At the room temperature, the sections rinsed with tap water and differentiated with hydrochloric acid alcohol for 3-8 sec, 
then the slices were immersed in $70 \%$ alcohol at $5 \mathrm{~min}$, $80 \%$ alcohol at $5 \mathrm{~min}, 90 \%$ alcohol at $5 \mathrm{~min}$ and $100 \%$ alcohol at 5 min twice, soaked in xylene at 10 min twice, and sealed with neutral balsam. All specimens were examined by two pathologists who were blinded to the experimental protocol. The sections were observed by light microscopy (magnification, $\mathrm{x} 10)$.

Isolation of rat primary lung fibroblasts. Normal rat primary fibroblasts from female Wistar rats were prepared and cultured as previously described (42). The cells were cultured in DMEM containing $15 \%$ fetal bovine serum (Gibco; Thermo Fisher Scientific, Inc.), $100 \mathrm{U} / \mathrm{ml}$ penicillin and $100 \mathrm{mg} / \mathrm{ml}$ streptomycin at $37^{\circ} \mathrm{C}$ in a $5 \% \mathrm{CO}_{2}$ incubator. Upon reaching confluence, the cells were trypsinized, counted, seeded into culture flasks at a density of $10^{4} / \mathrm{ml}$ and used in the following experiments. All experiments were performed using cells between passages 2 and 6 .

Western blotting. Lung tissues and fibroblasts were homogenized in cold RIPA lysis buffer, which contained $50 \mathrm{mM}$ Tris (pH 7.4),150 mM NaCl, $1 \%$ Triton $\mathrm{X}-100,1 \%$ sodium deoxycholate, $0.1 \%$ SDS, $1 \mathrm{mM}$ sodium orthovanadate, $1 \mathrm{mM}$ sodium fluoride, $1 \mathrm{mM}$ EDTA and $1 \mu \mathrm{g} / \mathrm{ml}$ leupeptin. Total protein was quantified using a bicinchoninic acid assay kit. The western blot protocol was an adaptation of a previously described (43). Briefly, equal amounts of protein (50 $\mu \mathrm{g}$ per lane) were separated on $10 \%$ SDS-PAGE gels and electro-blotted onto nitrocellulose membranes (EMD Millipore). The membranes were then blocked with 5\% non-fat milk in Tris-buffered saline with $0.1 \%$ Tween-20 (TBS-T) for $1 \mathrm{~h}$ at room temperature, and incubated at $4^{\circ} \mathrm{C}$ overnight with the following primary antibodies: Anti-Bcl-2 (1:500; cat. no. AB112), anti-Bax (1:500; cat.no.2772), anti-caspase-3 (1:200; cat.no. 9661), anti-cyclin A (1:500; cat. no. AF2524), anti-cyclin D (1:500; cat. no. 2922), anti-cyclin E (1:500; cat. no. 20808), anti-PCNA (1:500; cat. no. 2586), anti-p-AKT (1:500; cat. no. 9271), anti-t-AKT (1:500; cat. no. 9272), anti-p-CaMKII (1:500; cat. no. 12716) and anti-t-CaMKII (1:500; cat. no. 3362). The primary antibodies were purchased from Cell Signaling Technology, Inc and the Beyotime Institute of Biotechnology. After three rinses with TBS-T for $10 \mathrm{~min}$ each, the membranes were incubated with HRP-conjugated secondary antibodies (mouse; 1:5,000; cat. no. ZB2305; rabbit; 1:5,000; cat. no. ZB2301; Zhongshan Golden Bridge Bio-technology) for $1 \mathrm{~h}$ at room temperature. For immunodetection, the membranes were incubated with ECL reagents (Applygen Technologies, Inc.). Protein expression was semi-quantified using Quantity One software (version 4.6.2; Bio-Rad Laboratories, Inc.) with $\beta$-actin and GAPDH as the loading controls.

MTT assay. Fibroblasts $\left(1 \times 10^{4}\right.$ cells/well) were cultured in 96-well microtiter plates with serum-free DMEM for $24 \mathrm{~h}$ to induce growth arrest at $37^{\circ} \mathrm{C}$ in a $5 \% \mathrm{CO}_{2}$ incubator. $\mathrm{BLM}$ and baicalin were diluted in PBS and then purified using a filter with a $0.22-\mu \mathrm{m}$ pore size (Millex-GS; EMD Millipore). Then, $190 \mu$ l filtered PBS was added to DMEM in each control group. The cells were incubated with $190 \mu \mathrm{l}$ different concentrations of $\operatorname{BLM}(0.1,1.0,10,20$ or $40 \mu \mathrm{g} / \mathrm{ml})$ and baicalin $(20,40,60$ or $80 \mu \mathrm{g} / \mathrm{ml})$ for $24 \mathrm{~h}$ at $37^{\circ} \mathrm{C}$ in a $5 \% \mathrm{CO}_{2}$ incubator and treated for $4 \mathrm{~h}$ in medium containing $0.5 \%$ MTT $10 \mu \mathrm{l}$ (at $37^{\circ} \mathrm{C}$ ). After removing the supernatant, $150 \mu \mathrm{l}$ dimethyl sulfoxide was added to each well and the plates were mixed on a plate shaker for $10 \mathrm{~min}$ at room temperature. The absorbance of each sample was determined using a microplate reader at $490 \mathrm{~nm}$.

Cell cycle analysis. To study alterations to the cell cycle induced by BLM, the proportion of fibroblasts in the $\mathrm{G}_{0} / \mathrm{G}_{1}, \mathrm{~S}$ and $\mathrm{G}_{2} / \mathrm{M}$ phases was analyzed by flow cytometry, as previously reported (44). The detection procedure was performed according to the manufacturer's instructions, using a Cell cycle and apoptosis detection kit (Beyotime Institute of Biotechnology; cat. no. C1052). Following drug treatment at special time intervals, the cells were subjected with harvested by trypsinization, centrifuged at $300 \mathrm{x}$ g for $5 \mathrm{~min}$ at room temperature and then resuspended in $1 \mathrm{ml}$ cold PBS. Following two washes with PBS, the cells were resuspended and fixed using $70 \%$ cold ethanol and stored at $4^{\circ} \mathrm{C}$ for $\geq 2 \mathrm{~h}$ until use. Prior to cell cycle analysis, the fixed cells were centrifuged at $300 \mathrm{x} \mathrm{g}$ for $5 \mathrm{~min}$ at room temperature, and the supernatant was discarded. Each sample was resuspended in a mixed solution at room temperature, which contained $500 \mu \mathrm{l}$ staining buffer, $10 \mu 1$ RNase A and $25 \mu 1$ propidium iodide. Then, the suspension was mixed and incubated at $37^{\circ} \mathrm{C}$ for $30 \mathrm{~min}$ in the dark. Cells were filtered using 400-mesh sieves prior to analysis using a flow cytometer (C6 type; BD Biosciences). The data of the experiment was exported to Excel 2007 (Microsoft Corporation) and SPSS 19.0 (SPSS, Inc.) was used to analyze the statistical significance.

Measurement of $\left[\mathrm{Ca}^{2+}\right]_{i}$. Fibroblasts at a density of $10^{4} / \mathrm{ml}$ were incubated with a working solution containing $10 \mathrm{mM}$ Fluo-3/AM (acetoxymethyl ester; Molecular Probes; Thermo Fisher Scientific, Inc.) and $0.03 \%$ PluronicF-127, at $37^{\circ} \mathrm{C}$ for $40 \mathrm{~min}$. The cells were then rinsed twice with Tyrode solution to move any remaining dye. Changes in $\left[\mathrm{Ca}^{2+}\right]_{\mathrm{i}}$ levels were indicated by fluorescence intensity (FI). The cellular FI of Fluo-3/AM was detected for 5 min using a laser scanning confocal microscope (magnification, x10; Olympus Corporation) with an emission wavelength of $530 \mathrm{~nm}$ and excitation wavelength of $488 \mathrm{~nm}$. FI was assessed in 10 randomly selected cells, and the average intensity was determined.

Statistical analysis. Data were analyzed using SPSS 19.0 (45) and are presented as the mean \pm SEM. Statistical analysis was performed using one-way ANOVA followed by Tukey's test, which was used for the comparison of $>3$ groups. $\mathrm{P}<0.05$ was considered to indicate a statistically significant difference.

\section{Results}

Baicalin attenuates lung fibrosis, and reduces Hyp content and collagen protein expression in a BLM-induced rat model of pulmonary fibrosis. A significant increase in the Hyp content was observed following BLM administration in the model group, compared with the sham group (Fig. 1A). However, this was significantly inhibited by treatment with $50 \mathrm{mg} / \mathrm{kg}$ baicalin, which had no significant effect on the sham group. To further investigate the effects of baicalin in the pathogenesis 


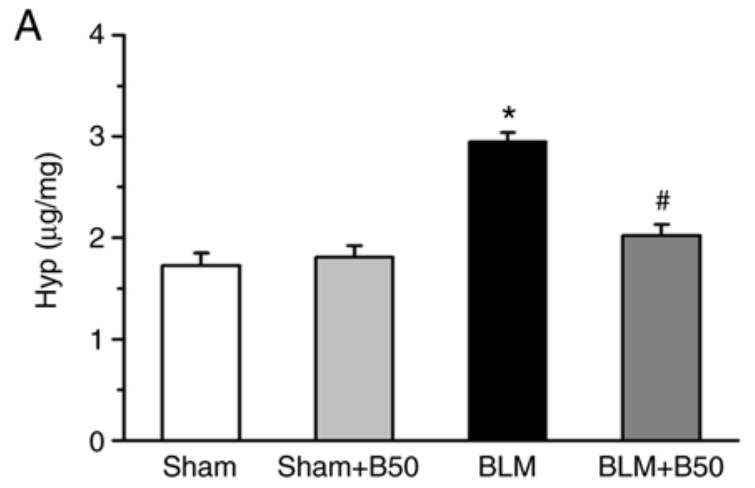

B

C

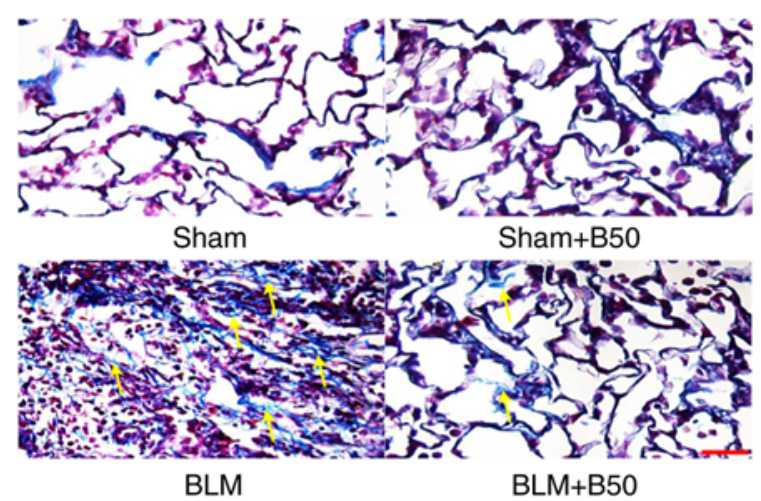

$\mathrm{E}$

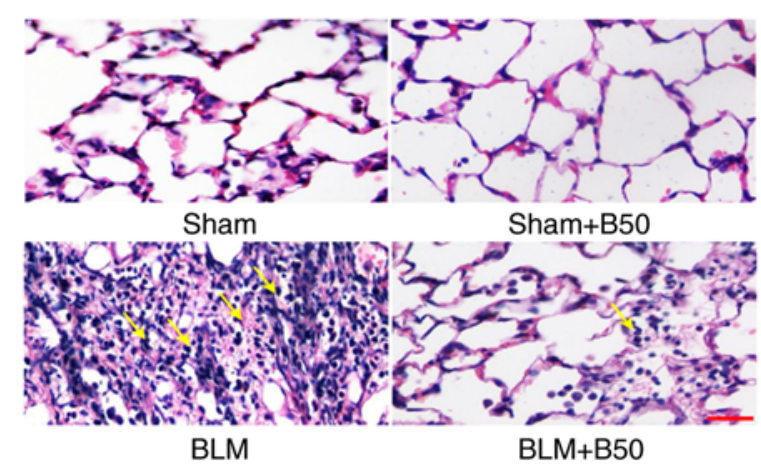

D
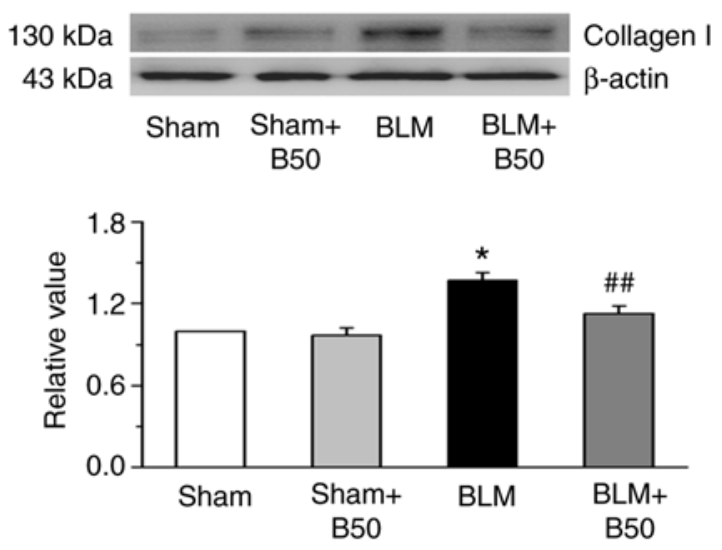
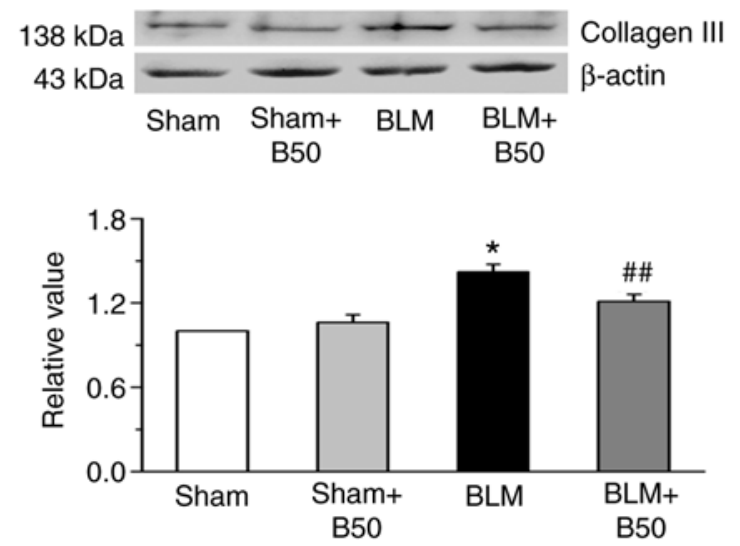

Figure 1. Baicalin attenuates lung fibrosis, Hyp content and collagen expression in a rat model of BLM-induced pulmonary fibrosis. (A) Effect of $50 \mathrm{mg} / \mathrm{kg}$ baicalin on Hyp content. Lung tissue morphology was examined by (B) hematoxylin-eosin staining and (C) Masson staining. The yellow arrows indicate morphological damage to the lung. Scale bar, $50 \mu \mathrm{m}$. (D) Collagen I and (E) collagen III protein expression were measured using western blot. Data are presented as the mean \pm SEM from $\geq 3$ separate experiments. ${ }^{*} \mathrm{P}<0.05$ vs. the sham group. ${ }^{\#} \mathrm{P}<0.05$ and ${ }^{\# \#} \mathrm{P}<0.01$ vs. the BLM group. Hyp, hydroxyproline; Sham, sham group; BLM, bleomycin; B50, $50 \mathrm{mg} / \mathrm{kg}$ baicalin.

of BLM-induced lung fibrosis, lung tissue morphology was examined by H\&E and Masson staining. At day 28, the lung tissues of BLM group exhibited severe fibrosis compared with the sham group (Fig. 1B), which included inflammatory cell infiltration and alveolar hemorrhage. It was also found that the alveoli were enlarged and the alveolar interstitium was thickened, as indicated by yellow arrows. Furthermore, Masson's staining demonstrated abundant collagen deposition (yellow arrows; Fig. 1C). Treatment with $50 \mathrm{mg} / \mathrm{kg}$ baicalin significantly reduced BLM-induced pathological changes, which included collagen deposition, and damage to the lung structure and interstitium. However baicalin treatment did not have a significant effect on the sham group (Fig. 1B and C).
Baicalin also suppressed the BLM-induced expression of collagen I and III (Fig. 1D and E). The results suggested that baicalin had a protective role during BLM-induced pulmonary fibrosis and lung tissue apoptosis.

Baicalin attenuates the inflammatory response, and decreases $T G F-\beta 1$ and TNF- $\alpha$ expression levels in a rat model of BLM-induced pulmonary fibrosis. At day 28 , the total number of cells in the BALF of rats treated with BLM $(5 \mathrm{mg} / \mathrm{kg})$ and baicalin $(\mathrm{B} 50 \mathrm{mg} / \mathrm{kg}$ ) was determined. The total number of cells in the BLM-treated group was significantly increased (5.26 \pm 0.31$)$ compared with the sham group $(4.07 \pm 0.34$; Fig. 2A). However, the increase in the total cell number was 

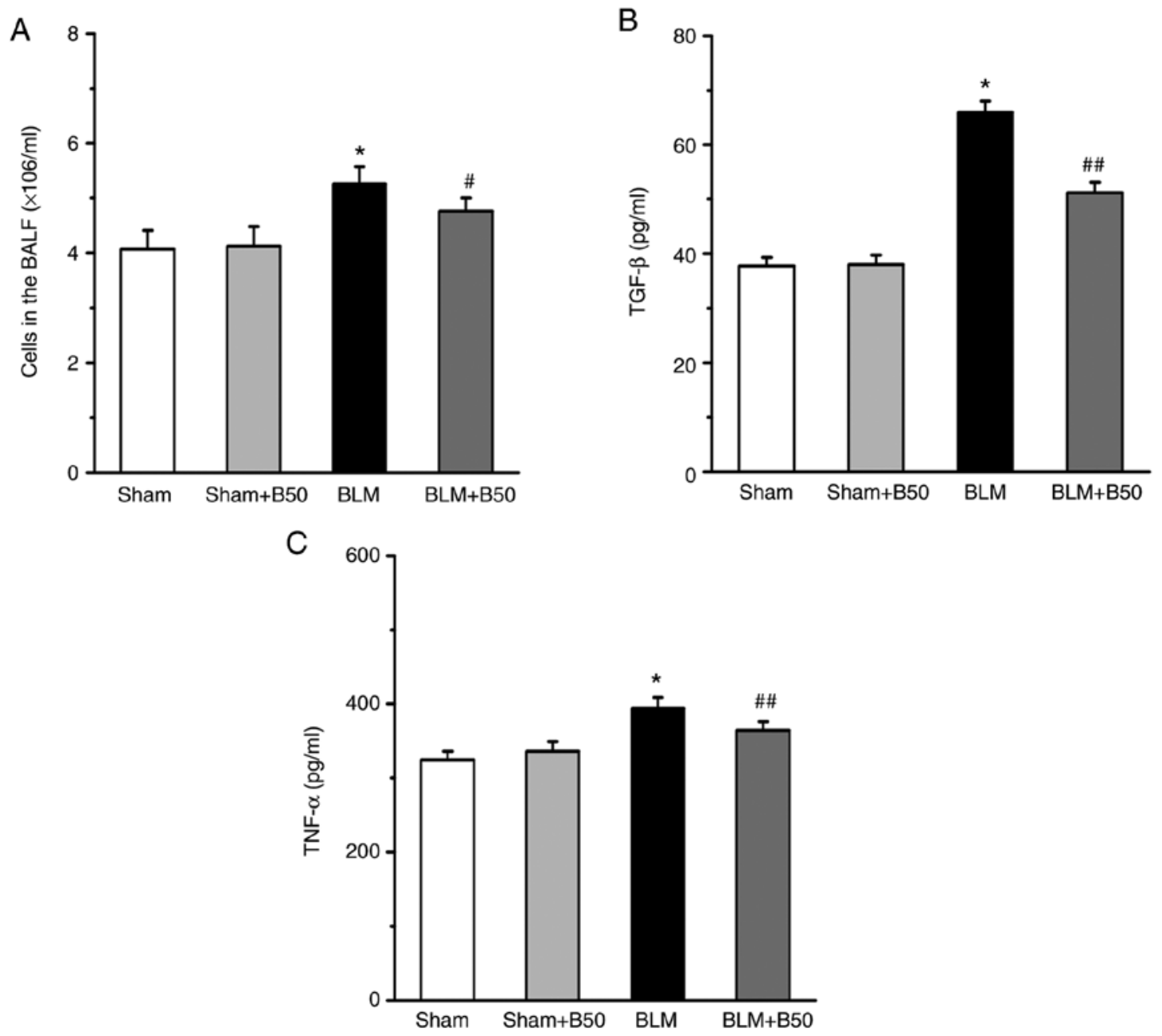

Figure 2. Baicalin reduces the inflammatory response, and TGF- $\beta 1$ and TNF- $\alpha$ expression levels in BLM-induced pulmonary fibrosis. (A) Total number of cells in the BALF of rats treated with BLM $(5 \mathrm{mg} / \mathrm{kg})$ and baicalin $(50 \mathrm{mg} / \mathrm{kg})$. Expression levels of (B) TGF- $\beta 1$ and (C) TNF- $\alpha$ in BALF, determined by ELISA. Data are presented as the mean \pm SEM from $\geq 3$ separate experiments. ${ }^{~} \mathrm{P}<0.05$ vs. the sham group. ${ }^{\#} \mathrm{P}<0.05$ and ${ }^{\# \#} \mathrm{P}<0.01$ vs. the BLM group. TGF, transforming growth factor; TNF, tumor necrosis factor; BALF, bronchial alveolar lavage fluid; Sham, sham group; BLM, bleomycin; B50, $50 \mathrm{mg} / \mathrm{kg}$ baicalin.

decreased by the application of $50 \mathrm{mg} / \mathrm{kg}$ baicalin $(4.76 \pm 0.24)$, while there was no significant difference between the sham group and the sham + baicalin $50 \mathrm{mg} / \mathrm{kg}$ group $(4.12 \pm 0.36)$. The expression levels of TGF- $\beta 1$ and TNF- $\alpha$ in the BALF were quantified by ELISA, which revealed that both TGF- $\beta 1$ and TNF- $\alpha$ were significantly upregulated in the BALF of the BLM group (65.92 \pm 2.1 and $394 \pm 15$, respectively) compared with the sham group $(37.68 \pm 1.6$ and $324 \pm 12$, respectively). However, baicalin significantly decreased TGF- $\beta 1$ and TNF- $\alpha$ expression (51.2 \pm 1.9 and $364 \pm 12$, respectively) in BLM-treated rats. Moreover, baicalin did not affect the expression of TGF- $\beta 1$ and TNF- $\alpha$ under sham conditions $(38.01 \pm 1.7$ and $336 \pm 13$, respectively; Fig. 2B and C).

Baicalin attenuates oxidative stress-associated damage. To investigate whether baicalin contributes to oxidative stress, the activities of GSH-px, T-SOD and GSH, as well as the serum MDA content were determined. It was demonstrated that GSH-px, T-SOD and GSH activities were decreased significantly in the serum of the $5 \mathrm{mg} / \mathrm{kg}$ BLM group $(738 \pm 13,186 \pm 11$ and $795 \pm 26$, respectively) compared with the sham group $(809 \pm 14,224.7 \pm 13$ and $945 \pm 25$, respectively;
Fig. 3A-C). However, treatment with $50 \mathrm{mg} / \mathrm{kg}$ baicalin significantly increased the activities of GSH-px, T-SOD and GSH $(769 \pm 18,212 \pm 12$ and $838 \pm 23$, respectively). Furthermore, the level of serum MDA, an index of lipid peroxidation (46) was significantly increased in the $5 \mathrm{mg} / \mathrm{kg}$ BLM group $(5.39 \pm 0.47)$ compared with the sham group (4.33 \pm 0.33 ; Fig. 3D), after the administration of $50 \mathrm{mg} / \mathrm{kg}$ baicalin, BLM-mediated lipid peroxidation was significantly decreased (4.69 \pm 0.39$)$. However, $50 \mathrm{mg} / \mathrm{kg}$ baicalin had no obvious effect on oxidative damage in the sham group $(4.29 \pm 0.36)$.

Baicalin inhibits BLM-induced apoptotic protein expression in rat lung tissues. To investigate whether baicalin is involved in lung tissue apoptosis, TUNEL staining was conducted. Compared with the sham group, a significant increase in TUNEL-positive cells (yellow arrows) was observed in the BLM group (Fig. 4A and B). Furthermore, the administration of $50 \mathrm{mg} / \mathrm{kg}$ baicalin inhibited the appearance of TUNEL-positive cells in the BLM group, which was indicated in the yellow arrows, but not the sham group. In addition, the mechanism of baicalin-induced lung 
A

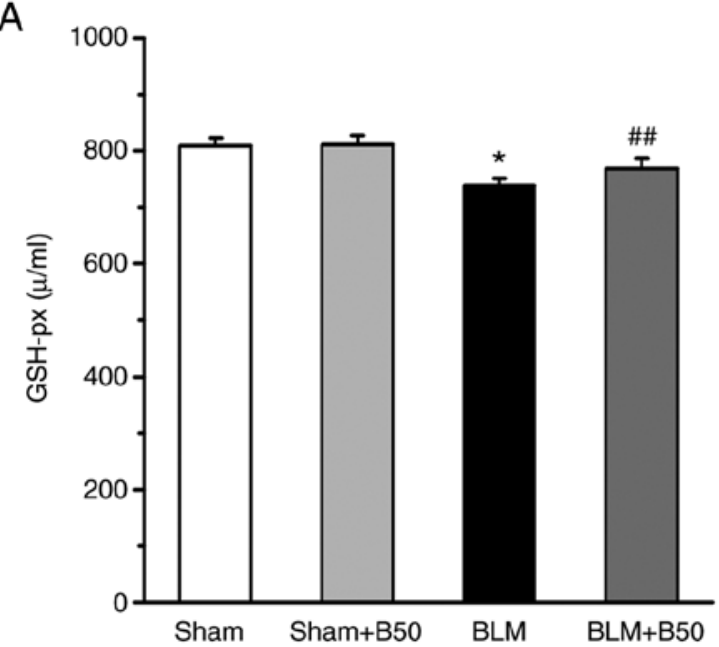

C

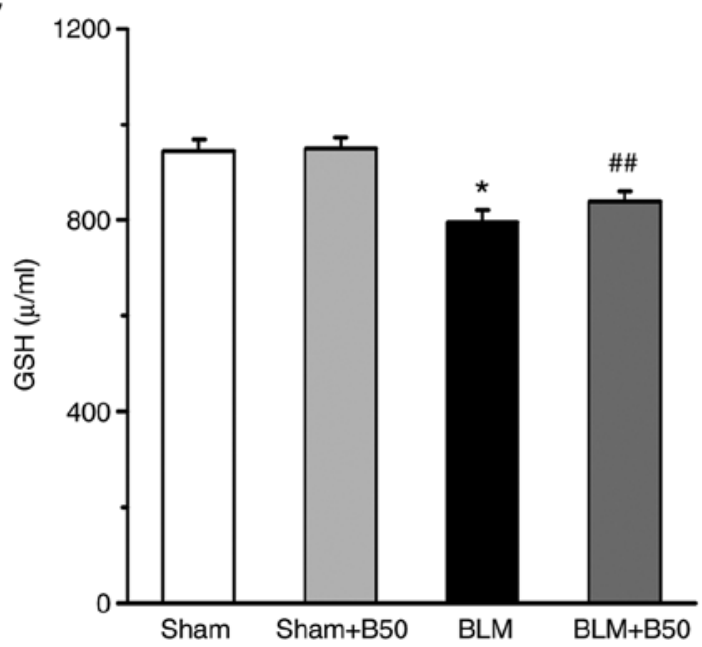

B

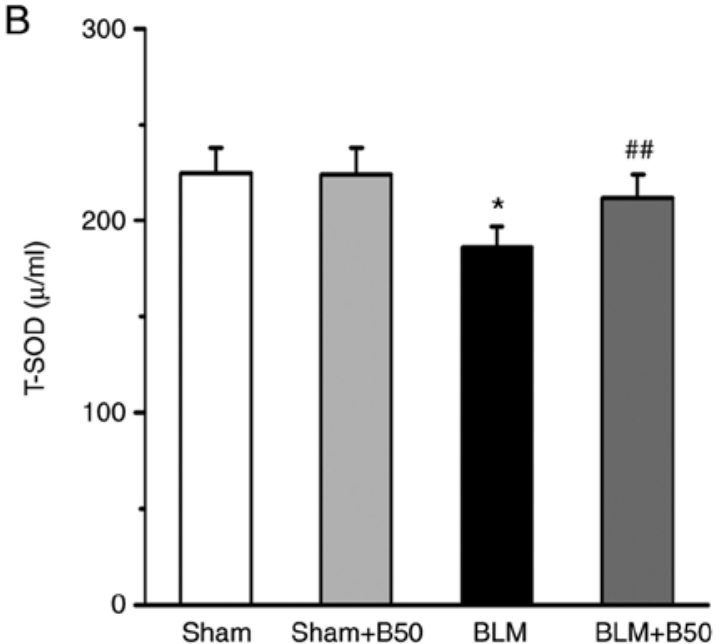

D

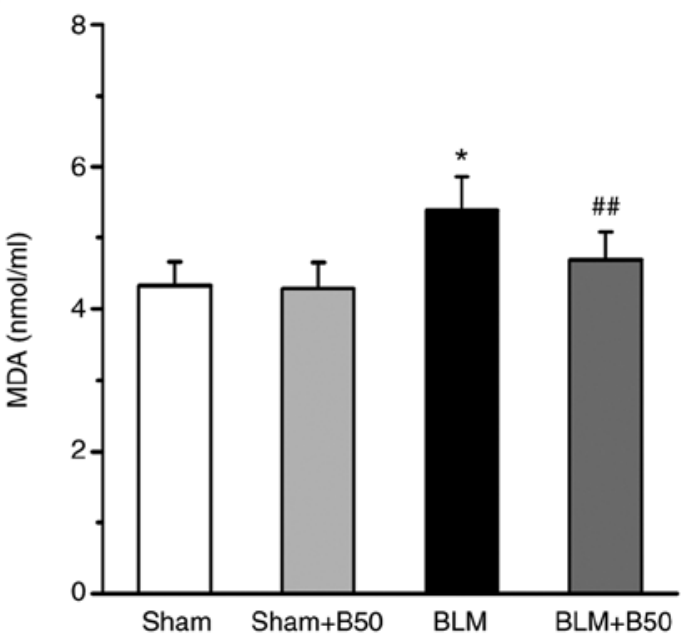

Figure 3. Baicalin decreases BLM-induced oxidative stress damage. The effect of $50 \mathrm{mg} / \mathrm{kg}$ baicalin on (A) GSH-px, (B) T-SOD and (C) GSH activities, and (D) the MDA content of lung tissues. Data are presented as the mean \pm SEM from $\geq 3$ separate experiments. ${ }^{*} \mathrm{P}<0.05$ vs. the sham group. ${ }^{\# t} \mathrm{P}<0.01 \mathrm{vs}$. the $\mathrm{BLM}$ group. BLM, bleomycin; GSH-px, glutathione peroxidase; T-SOD, total superoxide dismutase; GSH, glutathione; MDA, malondialdehyde; Sham, sham group; BLM, bleomycin; B50, $50 \mathrm{mg} / \mathrm{kg}$ baicalin.

tissue apoptosis was investigated. Bcl-2 and Bax are localized on the mitochondrial membrane and play important roles in apoptosis (47). Bcl-2 is known to be anti-apoptotic, whereas Bax is a pro-apoptotic protein (47). Therefore, in the present study, the effect of baicalin on the protein expression levels of Bcl-2 and Bax were investigated. The data showed that the expression levels of Bcl-2 were downregulated, while that of Bax was upregulated by BLM. Moreover, baicalin (50 $\mathrm{mg} / \mathrm{kg}$ ) increased Bcl-2, and suppressed Bax protein expression in rat lung tissues (Fig. 4C and D). Pro-caspase-3 is cleaved and activated to form caspase- 3 by originator caspases (including caspase 2, $8,9,10,11$ and 12) in response to apoptotic stimuli (48). In addition, BLM promoted the protein expression of caspase-3, an effect which was primarily blocked by $50 \mathrm{mg} / \mathrm{kg}$ baicalin treatment (Fig. 4E). However, baicalin had no significant effect on the expression of Bcl-2, Bax and caspase- 3 in the sham group.

Baicalin reverses BLM-induced fibroblast proliferation, cyclin protein expression and cell cycle progression in vivo.
Following BLM treatment, MTT was used to examine the effect of baicalin on the viability of rat lung fibroblasts. After a 24-h treatment period $(1.0,10,20$ or $40 \mu \mathrm{g} / \mathrm{ml}$ BLM) caused a significant dose-dependent increase in lung fibroblast viability, compared with that of the control group (Fig. 5A). With regards to the safety of the drug, $20 \mu \mathrm{g} / \mathrm{ml}$ BLM was selected for the following experiments. To demonstrate the effect of baicalin on lung fibroblasts, the dose-dependent effect was examined. Treatment with 40,60 or $80 \mu \mathrm{g} / \mathrm{ml}$ baicalin reduced cell viability at $24 \mathrm{~h}$, while $20 \mu \mathrm{g} / \mathrm{ml}$ baicalin failed to reduce cell viability under $20 \mu \mathrm{g} / \mathrm{ml}$ BLM treatment. Among the different treatment doses, $80 \mu \mathrm{g} / \mathrm{ml}$ baicalin exerted the most significant inhibitory effect (Fig. 5B). Therefore, unless otherwise stated, all subsequent experiments were performed under these conditions ( $24 \mathrm{~h}, 20 \mu \mathrm{g} / \mathrm{ml} \mathrm{BLM}$ and $80 \mu \mathrm{g} / \mathrm{ml}$ baicalin). Western blot analysis was conducted to observe the expression levels of cyclin proteins in lung fibroblasts treated with $80 \mu \mathrm{g} / \mathrm{ml}$ baicalin. The results indicated that $20 \mu \mathrm{g} / \mathrm{ml} \mathrm{BLM}$ significantly increased the expression of cyclin A, cyclin D, cyclin E, as well as PCNA in rat fibroblasts (Fig. 5C-F). CaMKII is reported to be activated by intracellular $\mathrm{Ca}^{2+}(35)$, 
A

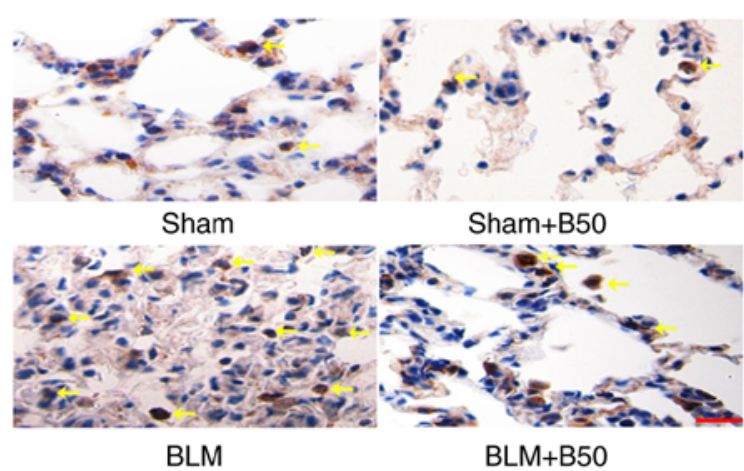

C
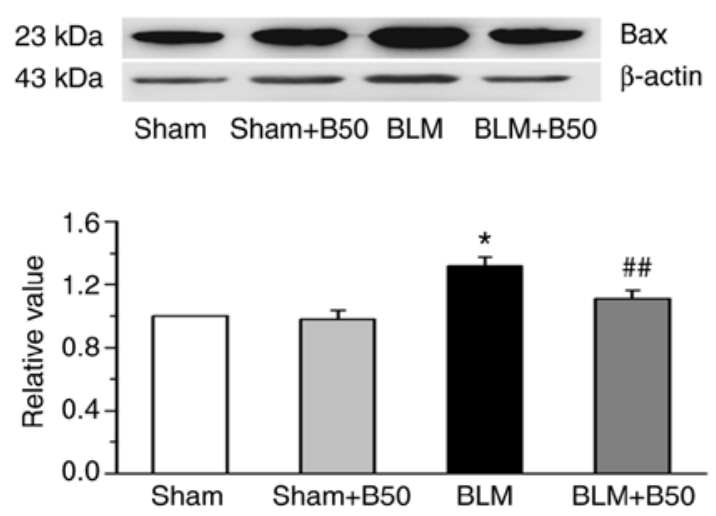

B

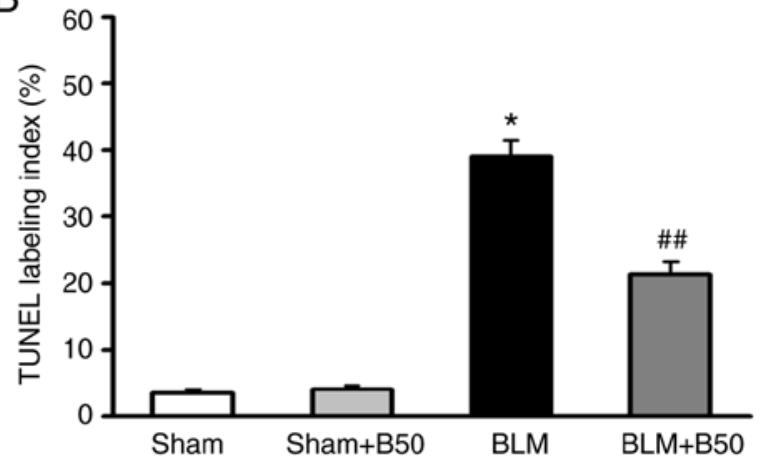

D
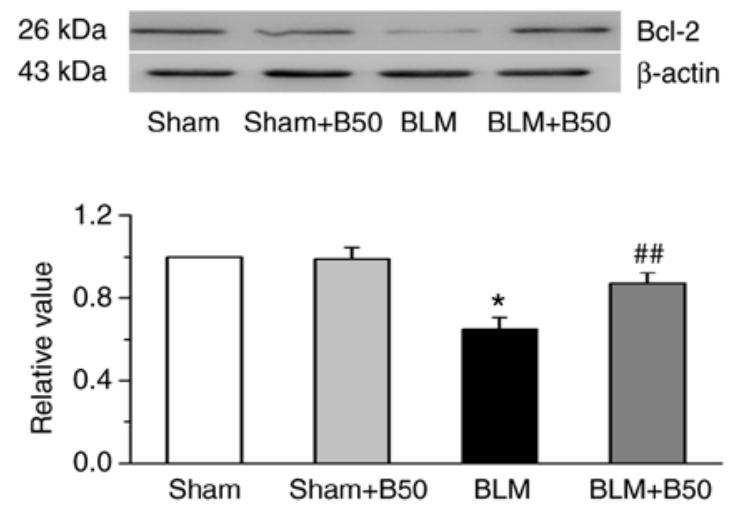

E

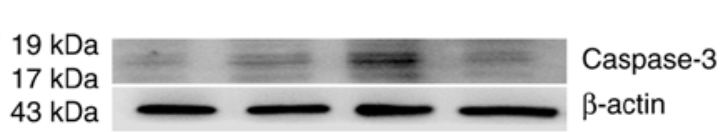

Sham Sham+B50 BLM BLM+B50

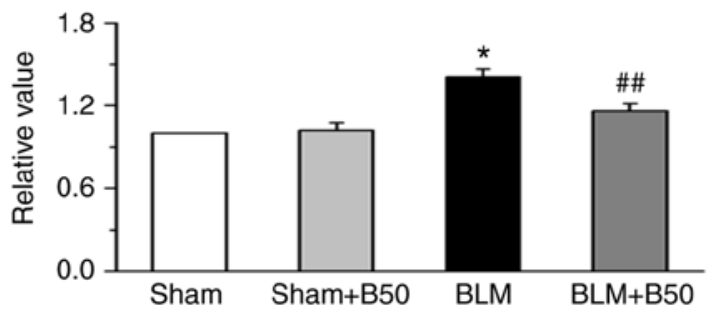

Figure 4. Baicalin inhibits BLM-induced alterations to apoptotic protein expression in the lung tissues of a rat model of BLM-induced pulmonary fibrosis. (A) TUNEL staining and (B) quantification of lung tissue sections. The yellow arrows indicate TUNEL-positive cells. Scale bar, $50 \mu \mathrm{m}$. (C) Bax expression in BLM-treated rats was decreased by $50 \mathrm{mg} / \mathrm{kg}$ baicalin. (D) Effect of baicalin treatment on Bcl-2 expression. (E) BLM-induced caspase 3 expression was decreased by $50 \mathrm{mg} / \mathrm{kg}$ baicalin. Data are presented as the mean \pm SEM from $\geq 3$ separate experiments. ${ }^{*} \mathrm{P}<0.05$ vs. the sham group. ${ }^{\# \#} \mathrm{P}<0.01$ vs. the BLM group. Sham, sham group; BLM, bleomycin; B50, $50 \mathrm{mg} / \mathrm{kg}$ baicalin.

and the western blot results indicated a significant increase in p-AKT and p-CaMKII expression levels in the BLM group (Fig. 6A and B). However, $80 \mu \mathrm{g} / \mathrm{ml}$ baicalin suppressed the expression of cyclin A,D and E, PCNA, p-AKT and p-CaMKII (Figs. 5C-F and 6A and B).

Additionally, BLM increased the percentage of cells in the S and $\mathrm{G}_{2} / \mathrm{M}$ phases of the cell cycle. Baicalin inhibited fibroblast cell cycle progression and promoted arrest at the $\mathrm{G}_{0} / \mathrm{G}_{1}$ phase (Fig. 6C). Moreover, laser scanning confocal microscopy indicated that the increase in $\left[\mathrm{Ca}^{2+}\right]_{\mathrm{i}}$ in BLM-treated fibroblasts was significantly attenuated by baicalin treatment (Fig. 6D and E). The results suggested that baicalin protected cell cycle activity and inhibited fibroblast proliferation, ultimately contributing to pulmonary fibrosis.

\section{Discussion}

Pulmonary fibrosis is the final stage of several diffuse parenchymal lung diseases, and is characterized by excessive matrix deposition and destruction of the lung architecture, eventually resulting in respiratory insufficiency (49). IPF is a progressive, end stage disease, and the pathophysiological basis of the disease has been a topic of debate over the last few decades (8). Animal models of BLM-induced lung fibrosis are widely used to study IPF (50), though the precise mechanism of IPF is still unclear. Previous studies have demonstrated that baicalin exhibits strong antitumor activity and inhibits apoptosis of tumor cells (51-53). Therefore, in the present study, the mechanisms underlying the effect of baicalin on pulmonary 
A

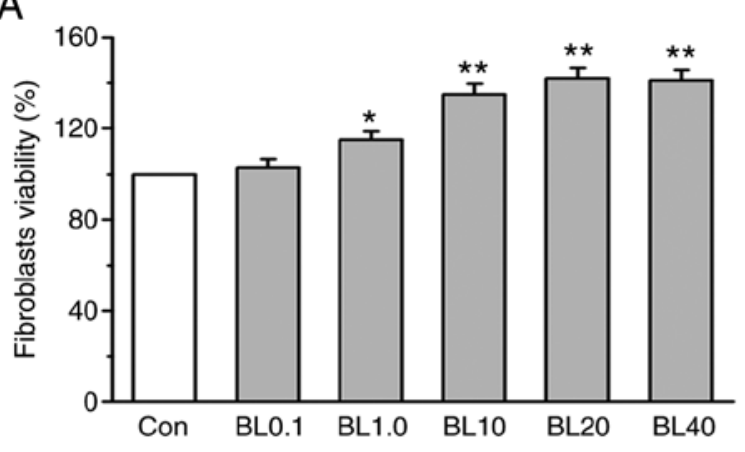

C
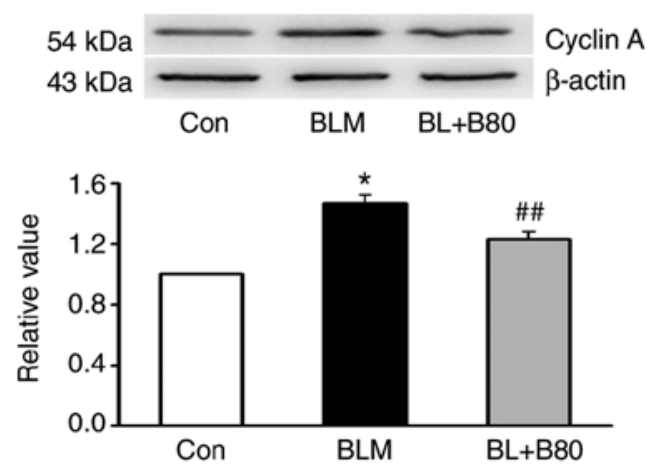

$\mathrm{E}$
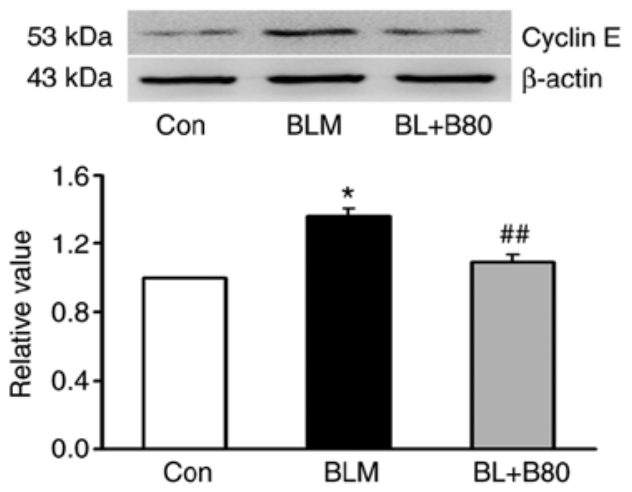

B

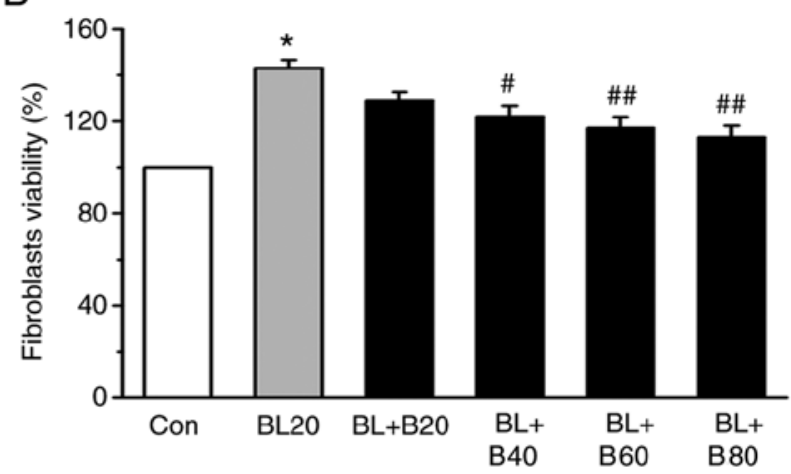

D

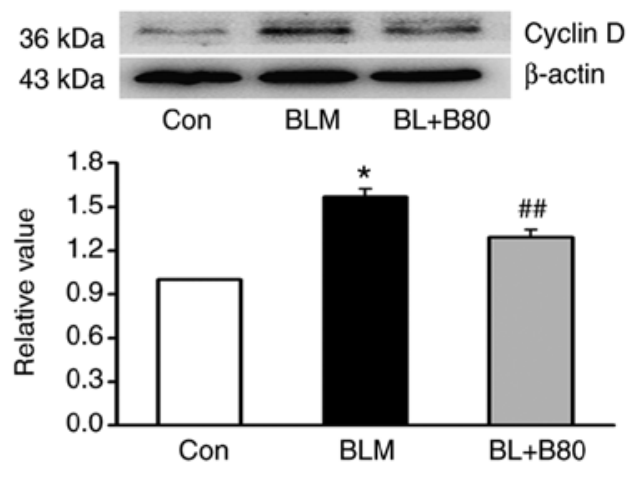

$\mathrm{F}$
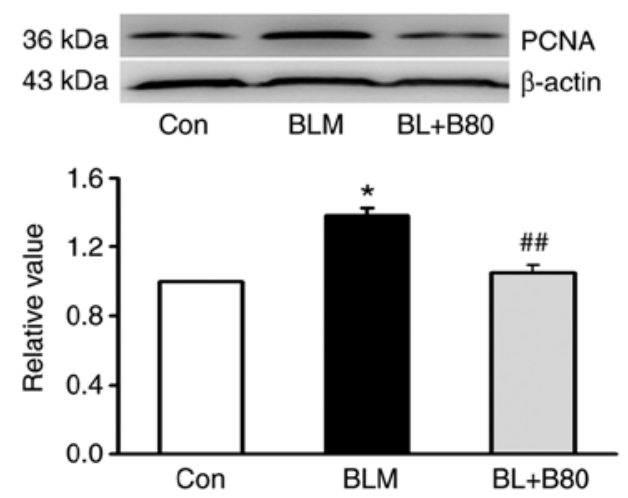

Figure 5. Baicalin reverses BLM-induced fibroblast proliferation, and the expression of PI3K/AKT and CaMKII in vivo. Lung fibroblasts were growth-arrested for $24 \mathrm{~h}$ and subsequently treated with different concentrations of BLM $(0.1,1.0,10,20$ and $40 \mu \mathrm{g} / \mathrm{ml})$. (A) Effect of BLM on lung fibroblast viability. (B) Dose-dependent effects of baicalin $(20,40,60$ and $80 \mu \mathrm{g} / \mathrm{ml})$ on lung fibroblast viability under the treatment of BLM $(20 \mu \mathrm{g} / \mathrm{ml})$. BLM-induced (20 $\mu \mathrm{g} / \mathrm{ml})$ upregulation of (C) cyclin A, (D) cyclin D, (E) cyclin E and (F) PCNA protein expression was reduced by baicalin (80 $\mu \mathrm{g} / \mathrm{ml})$ in lung fibroblasts. Data are presented as the mean \pm SEM from $\geq 3$ separate experiments. ${ }^{*} \mathrm{P}<0.05$ and ${ }^{* *} \mathrm{P}<0.01$ vs. the Con group. ${ }^{*} \mathrm{P}<0.05$ and ${ }^{\# \#} \mathrm{P}<0.01$ vs. the BLM group. Con, control; BLM, bleomycin; BL, bleomycin; CaMKII, calcium/calmodulin-dependent kinase II; PCNA, proliferating cell nuclear antigen; BL0.1, $0.1 \mu \mathrm{g} / \mathrm{ml}$ bleomycin; BL1.0, $1.0 \mu \mathrm{g} / \mathrm{ml}$ bleomycin; BL10, $10 \mu \mathrm{g} / \mathrm{ml}$ bleomycin; BL20, $20 \mu \mathrm{g} / \mathrm{ml}$ bleomycin; BL40, $40 \mu \mathrm{g} / \mathrm{ml}$ bleomycin; B20, $20 \mathrm{mg} / \mathrm{kg}$ baicalin; B40, $40 \mathrm{mg} / \mathrm{kg}$ baicalin; B60, $60 \mathrm{mg} / \mathrm{kg}$ baicalin; B80, $80 \mathrm{mg} / \mathrm{kg}$ baicalin.

fibrosis was investigated, demonstrating that baicalin reversed BLM-induced lung tissue apoptosis and pulmonary fibrosis, attenuated oxidative stress and inhibited rat lung fibroblast proliferation, at least partly via the CaMKII and AKT pathways.

In a short period of time, BLM can induce inflammatory and fibrotic aberrations in the lung tissue, and intratracheal administration of BLM has been shown to increase the expression of fibrogenic cytokines such as TNF- $\alpha$, TGF- $\beta$, IL- $1 \beta$ and IL-6 (50). Pathological changes due to lung tissue inflammation were also observed in the present study, after exposure to BLM, a rapid increase in Hyp content and the infiltration of inflammatory cells was apparent, and alveolar septal thickening was indicated by H\&E and Masson staining. Conversely, rats in the BLM + baicalin group exhibited reduced inflammatory cell infiltration and collagen deposition in the lungs. In addition to a reduction in collagen I and III protein expression following baicalin treatment, these results indicated that baicalin attenuated BLM-induced pulmonary fibrosis.

Following administration of $5 \mathrm{mg} / \mathrm{kg}$ BLM, which emulates inflammatory stimulation (54), the total number of cells in the BALF was significantly increased, which was subsequently reduced by baicalin treatment $(5 \mathrm{mg} / \mathrm{kg})$. Previous studies have revealed that TNF- $\alpha$ is overexpressed 
A

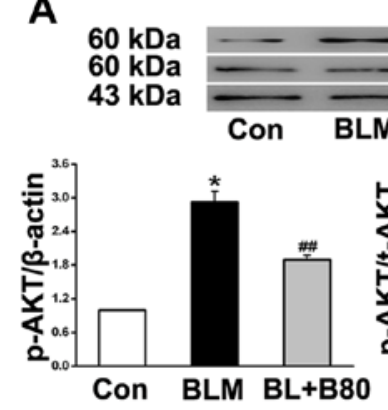

C

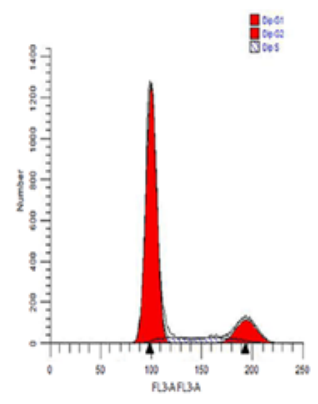

Con

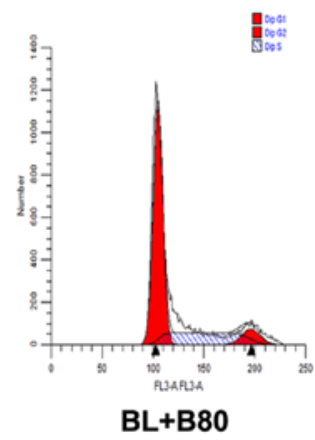

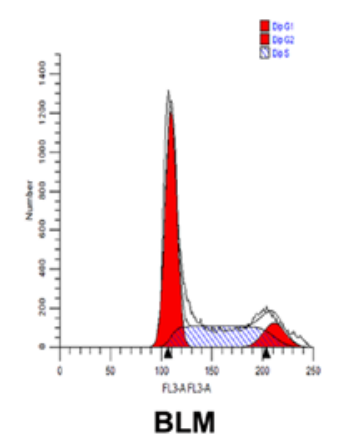

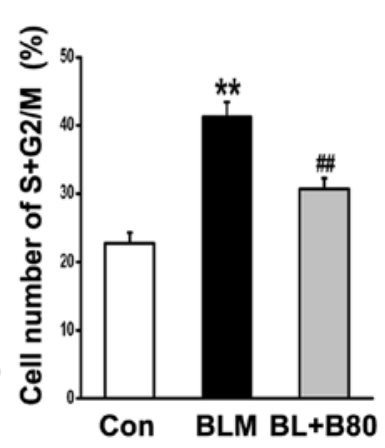

B
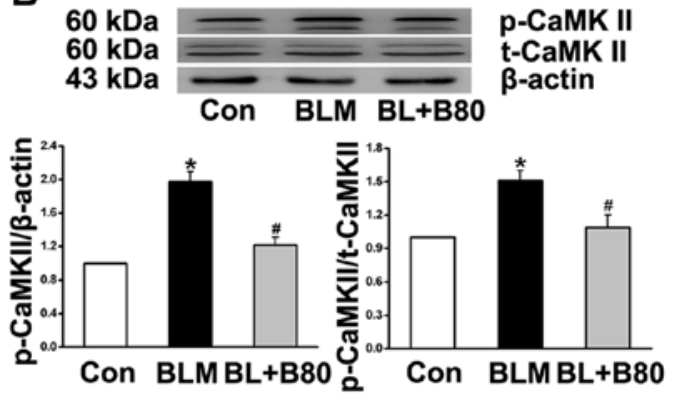

D

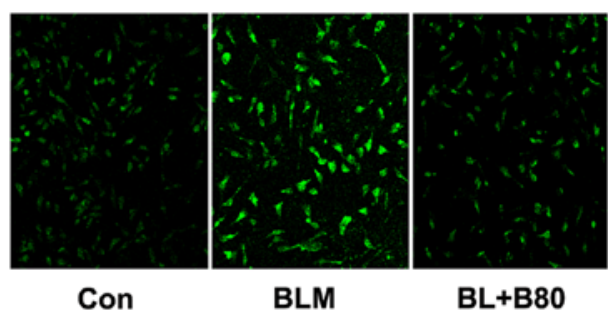

E

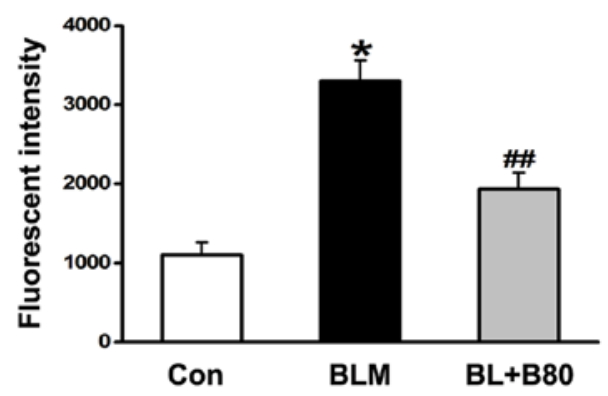

Figure 6. Baicalin decreases BLM-induced AKT and CaMKII protein phosphorylation and cell cycle progression in vivo. (A and B) BLM-induced upregulation of p-AKT and p-CaMKII protein expression was inhibited by baicalin $(80 \mu \mathrm{g} / \mathrm{ml})$ in lung fibroblasts (C) BLM promoted fibroblast cell cycle progression and increased the percentage of cells in the $\mathrm{S}$ and $\mathrm{G}_{2} / \mathrm{M}$ phases, while the proliferation indices were significantly decreased following baicalin treatment. (D) BLM-induced increase in $\left[\mathrm{Ca}^{2+}\right]_{\mathrm{i}}$ was significantly suppressed by baicalin $(\mathrm{n}=6)$ using laser scanning confocal microscopy (magnification, $\left.\mathrm{x} 10\right)$. (E) Quantification of $\left[\mathrm{Ca}^{2+}\right]_{\mathrm{i}}$ levels. Data are presented as the mean \pm SEM from $\geq 3$ separate experiments. ${ }^{*} \mathrm{P}<0.05$ and ${ }^{* *} \mathrm{P}<0.01$ vs. Con. ${ }^{* \prime} \mathrm{P}<0.01 \mathrm{vs}$. the $\mathrm{BLM}$ group. Con, control; BLM, bleomycin; BL, bleomycin; CaMKII, calcium/calmodulin-dependent kinase II; p, phosphorylated; B80, $80 \mathrm{mg} / \mathrm{kg}$ baicalin.

in the fibrotic lung tissues of animal models of BLM-induced pulmonary fibrosis (55-57), which serves a vital role in fibrotic progression (58). TGF- $\beta 1$ is also a crucial profibrotic cytokine $(59,60)$ and plays a central role in the mechanism of systemic sclerosis-associated pulmonary fibrosis $(61,62)$. In the present study, baicalin was identified to inhibit the expression of TGF- $\beta 1$ and TNF- $\alpha$ in the BALF of the BLM group. These results suggested that baicalin attenuates the pulmonary inflammation induced by BLM. Additionally, Moreover, the present results indicated that baicalin can significantly alleviated pulmonary fibrosis and inflammatory responses induced by BLM in rats. However, the anti-pulmonary fibrosis effect of baicalin has also been reported in other species and strains. Liu et al reported that baicalin alleviated silica-induced lung inflammation by suppressing IL-6 and IL-23, which reflects Th17 response and lung fibrosis in C57BL/6 mice (25). Baicalin inhibited BLM-induced pulmonary fibrosis in mice by upregulating Adenosine A2a receptor and downregulating TGF- $\beta 1$ and $\mathrm{p}$-ERK1/2 expression (26). The cross-species effect of baicalin also suggested that future studies should investigate the specific mechanism and underlying signaling pathways of baicalin in inhibiting pulmonary fibrosis in a murine model.

Previous studies have suggested that oxidative stress contributes to fibrosis in a variety of organs $(63,64)$, and that there is an imbalance between the generation of ROS (65-67). Therefore, in the present study, oxidative stress was assessed by detecting GSH-px, T-SOD and GSH activity, as well as the levels of MDA in the serum of fibrotic rats. It was demonstrated that in the BLM group, MDA levels were significantly increased, while GSH-px, T-SOD and GSH levels were reduced. By contrast, baicalin significantly reduced the MDA content, and simultaneously increased the levels of GSH-px, T-SOD and GSH. The results implied that baicalin significantly suppressed BLM-induced fibrosis and oxidative stress injury, which may explain the protective effects against BLM-induced pulmonary fibrosis.

The mechanisms of baicalin-associated lung tissue apoptosis were also investigated following BLM administration. 
Morphological evaluation demonstrated that $50 \mathrm{mg} / \mathrm{kg}$ baicalin decreased the number of TUNEL-positive cells in the lung tissue. Furthermore, the down-regulation of BLM-induced Bcl-2 expression was significantly reversed by baicalin treatment. Baicalin also reversed the BLM-associated increase in Bax and caspase- 3 expression levels, thus demonstrating that baicalin protects against apoptosis in pulmonary tissues.

Fibroblasts are critical cells for the pathogenesis of pulmonary fibrosis (68). In the present study, it was demonstrated that BLM promoted rat lung fibroblast viability in dose-dependent manner. Similar results have been reported in other studies. F2-isoprostanes mediated BLM (25, 50 and $100 \mu \mathrm{g} / \mathrm{ml}$ ) induced rat lung fibroblast proliferation and collagen synthesis, and the incubation time of bleomycin was $48 \mathrm{~h}$ (69). Additionally, NLRP3 participates in the regulation of epithelial-mesenchymal transition (EMT) in BLM-induced pulmonary fibrosis, the concentrations of bleomycin was treated to A549 cells were $0,40,80,120,160$ and $200 \mu \mathrm{M}$ for $24 \mathrm{~h}$ to study cell viability, and those added to RLE-6TN cells were $0,10,20,30,40,50$ and $60 \mu \mathrm{M}$ for $24 \mathrm{~h}$ (70). It has been shown that different cell types may be differentially effected by the same drug. In the present study, cell viability assays revealed that fibroblast proliferation was consistent at 20 and $40 \mu \mathrm{g} / \mathrm{ml} \mathrm{BLM}$, thus, $20 \mu \mathrm{g} / \mathrm{ml} \mathrm{BLM}$ treatment for $24 \mathrm{~h}$ was utilized for subsequent experimentation. Following the administration of different concentrations of baicalin $(40,60$ and $80 \mu \mathrm{g} / \mathrm{ml}$ ), the results indicated that 40, 60 and $80 \mu \mathrm{g} / \mathrm{ml}$ baicalin significantly reduced lung fibroblast viability in the $20 \mu \mathrm{g} / \mathrm{ml}$ BLM group, however, no significant effect was observed following treatment with $20 \mu \mathrm{g} / \mathrm{ml}$ baicalin. It has been reported that baicalin treatment $(50$ or $100 \mu \mathrm{M}$ for $24 \mathrm{~h}$ ) promoted the repair of DNA single-strand breaks and improved cell viability in $\mathrm{H}_{2} \mathrm{O}_{2}$-treated NIH3T3 mouse fibroblasts (71). Furthermore, baicalin $(25,50$ and $100 \mu \mathrm{g} / \mathrm{ml})$ reduced the colistin sulfate-induced apoptosis of PC12 cells in a dose-dependent manner (72). Additionally, baicalin (200 $\mu \mathrm{M}$ ) activated caspase-3 expression to induce apoptosis in SW620 human colorectal carcinoma cells (73). In clinical practice, baicalin displays good drug safety, and the present study further suggested that $80 \mu \mathrm{g} / \mathrm{ml}$ baicalin significantly reduced the viability of lung fibroblasts.

The cell cycle plays an important role in cell proliferation (74), but how the cell cycle progression responds to the baicalin remains unknown. The cell cycle is subdivided into four phases: DNA replication occurs during $S$ phase, and chromosome segregation occurs during $M$ phase. The $S$ and $M$ phases are separated by $\mathrm{G}_{1}$ (before DNA replication) and $\mathrm{G}_{2}$ (before mitosis) (75). Cyclin $A$ is essential for progression through the $S$ phase, and cyclin $D$ and $E$, are necessary for $G_{1} / S$ transition (76-78). The results of the present study demonstrated that BLM increased the expression of cyclin A, D and E, and PCNA in vitro, and increased the proportion of cells in the $\mathrm{S}$ and $\mathrm{G}_{2} / \mathrm{M}$ phases, suggesting that BLM induces proliferation via the cell cycle. In vitro, baicalin $(20 \mu \mathrm{g} / \mathrm{ml})$ decreased the BLM-induced protein expression levels of cyclin A, D and E, and PCNA, and the proportion of cells in the $S$ and $G_{2} / M$ phases. The PI3K/AKT pathway is involved in the regulation of several target proteins such as NF- $\kappa \mathrm{B}, \mathrm{p} 53$, glycogen synthase kinase- $3 \beta$, Bad and caspase- 9 that regulate cellular proliferation and apoptosis (43). Immunohistochemical analysis of lung biopsy specimens from patients with IPF revealed that fibroblasts within fibrotic foci expressed low levels of PTEN and upregulated levels of AKT (79). Fucoxanthin inhibited the TGF- $\beta 1$-induced expression of $\alpha$-SMA, type 1 collagen and IL- 6 , and inhibited the phosphorylation of p38, PI3K/AKT and Smad2/Smad3 in human pulmonary fibroblasts (80). Additionally, small interfering RNAs (siRNAs) against plasminogen activator inhibitor-1 (PAI-1) reduced the expression of type I and III collagen and increased the expression of caspase-3 in vivo, as well as inhibiting p-ERK1/2 and PI3K/AKT expression, and induced the proliferation of fibroblasts derived from rat models of BLM-induced fibrosis (81). It has also been shown that microRNA (miR)-155 reduces the expression of collagens and inhibits the formation of hypertrophic scar fibroblasts by targeting hypoxia-inducible factor- $1 \alpha$ via the PI3K/AKT signaling pathway (82). Additionally, activation of the adenosine subtype $2 \mathrm{~B}(\mathrm{~A} 2 \mathrm{~B})$ receptor mediated the inhibition of ET-1-induced fibroblast proliferation via the cAMP/Epac/PI3K/AKT signaling pathway (83). miR-542-5p mimic reduced the proliferation of mouse fibroblasts, and inhibited silica-induced pulmonary fibrosis by directly binding to integrin- $\alpha 6$, both effects at least partially via the FAK/PI3K/AKT signaling pathway (84). However, whether $\mathrm{PI} 3 \mathrm{~K}$ is involved in the effect of baicalin on pulmonary fibrosis, and its specific BLM-induced mechanism, has not yet been reported.

CaMKII is known to be activated by intracellular $\mathrm{Ca}^{2+}$ (35). He et al (85) reported that LPS induced a direct fibrogenic effect on lung fibroblasts by upregulating collagen expression and cell proliferation via the PI3K/AKT signaling pathway. However, the relationship between baicalin and the PI3K/AKT or CaMKII signaling pathways in pulmonary fibrosis has not been elucidated. The results of the present study suggested that BLM increased the phosphorylation of CaMKII and AKT, which was reversed by baicalin treatment. Moreover, baicalin significantly decreased BLM-induced $\left[\mathrm{Ca}^{2+}\right]_{\mathrm{i}}$ in lung fibroblasts. The results suggested that the CaMKII and AKT signaling pathways were involved in the inhibition of the cell cycle and proliferation of lung fibroblasts in rats treated with baicalin. Consistently, it has been reported that in certain cell types, $\mathrm{Ca}^{2+} /$ calmodulin-dependent protein kinases act upstream of AMPK $(86,87)$. Moreover, puerarin-mediated eNOS phosphorylation is dependent on AMPK signaling via CaMKII (38). An increase in ERK1/2 expression promotes CaMKII-induced matrix metalloproteinase-9 expression, resulting in the proliferation and migration of cardiac fibroblasts obtained from a rat model of pulmonary arterial hypertension (88). Furthermore, neokyotorphin induced the proliferation of fibroblasts, which required $\mathrm{Ca}^{2+}$ influx and the activation of PKA, CaMKII and MAPK/ERK (89).

Although the present study suggested that the protective effect of baicalin on pulmonary fibrosis may be via inhibiting the PI3K/AKT and CaMKII signaling pathways, the receptor and downstream target genes of these inhibitory signaling pathways, the mechanism in baicalin-treated cells requires further investigation. Thus, further studies will help to reveal how baicalin influences the CaMKII/PI3K/AKT complex.

In conclusion, the present study suggested that baicalin inhibited histopathological damage and lung fibroblast 
proliferation in BLM-induced pulmonary fibrosis, and that this effect was at least in part, mediated via the CaMKII and PI3K/AKT signaling pathways. The present results provide novel insights into the protective effects of baicalin in pulmonary fibrosis and the underlying mechanisms, which may become the theoretical basis for the use of baicalin in the management of IPF.

\section{Acknowledgements}

Not applicable.

\section{Funding}

No funding was received.

\section{Availability of data and materials}

The analyzed data sets generated during the present study are available from the corresponding author on reasonable request.

\section{Authors' contributions}

ZL designed the experiments. HZ performed the experiments. CL, LL and YR performed the animal experiments. JL, YG and KM performed the cell experiments and western blotting. $\mathrm{HZ}, \mathrm{DC}$ and $\mathrm{AL}$ analyzed the data. HZ and YR wrote the manuscript. $\mathrm{HZ}$ and $\mathrm{ZL}$ are accountable for all aspects of the work. All authors contributed to the interpretation of the data and critical revision of the manuscript. All authors have read and approved the final manuscript.

\section{Ethics approval and consent to participate}

All animal experiments were approved by the Medical Ethics Committee of the Harbin Medical University.

\section{Patient consent for publication}

Not applicable.

\section{Competing interests}

The authors declare that they have no competing interests.

\section{References}

1. Gross TJ and Hunninghake GW: Idiopathic pulmonary fibrosis. N Engl J Med 345: 517-525, 2001.

2. Selman M, Thannickal VJ, Pardo A, Zisman DA, Martinez FJ and Lynch JP III: Idiopathic pulmonary fibrosis: Pathogenesis and therapeutic approaches. Drugs 64: 405-430, 2004.

3. Thannickal VJ, Toews GB, White ES, Lynch JP III and Martinez FJ: Mechanisms of pulmonary fibrosis. Annu Rev Med 55: 395-417, 2004.

4. Raghu G, Freudenberger TD, Yang S, Curtis JR, Spada C, Hayes J, Sillery JK, Pope CE II and Pellegrini CA: High prevalence of abnormal acid gastro-oesophageal reflux in idiopathic pulmonary fibrosis. Eur Respir J 27: 136-142, 2006.

5. Ask K, Bonniaud P, Maass K, Eickelberg O, Margetts PJ, Warburton D, Groffen J, Gauldie J and Kolb M: Progressive pulmonary fibrosis is mediated by TGF-beta isoform 1 but not TGF-beta3. Int J Biochem Cell Biol 40: 484-495, 2008.
6. Gharaee-Kermani M, Gyetko MR, Hu B and Phan SH: New insights into the pathogenesis and treatment of idiopathic pulmonary fibrosis: A potential role for stem cells in the lung parenchyma and implications for therapy. Pharm Res 24: 819-841, 2007.

7. Wilkes DS, Chew T, Flaherty KR, Frye S, Gibson KF, Kaminski N, Klemsz MJ, Lange W, Noth I and Rothhaar K: Oral immunotherapy with type $\mathrm{V}$ collagen in idiopathic pulmonary fibrosis. Eur Respir J 45: 1393-1402, 2015.

8. King TE Jr, Pardo A and Selman M: Idiopathic pulmonary fibrosis. Lancet 378: 1949-1961, 2011.

9. Kinnula VL, Fattman CL, Tan RJ and Oury TD: Oxidative stress in pulmonary fibrosis: A possible role for redox modulatory therapy. Am J Respir Crit Care Med 172: 417-422, 2005.

10. Rydell-Törmänen K, Andréasson K, Hesselstrand R, Risteli J, Heinegård D, Saxne T and Westergren-Thorsson G: Extracellular matrix alterations and acute inflammation; developing in parallel during early induction of pulmonary fibrosis. Lab Invest 92: 917-925, 2012.

11. Jia L, Sun P, Gao H, Shen J, Gao Y, Meng C, Fu S, Yao H and Zhang G: Mangiferin attenuates bleomycin-induced pulmonary fibrosis in mice through inhibiting TLR4/p65 and TGF- $\beta 1 / \mathrm{Smad} 2 / 3$ pathway. J Pharm Pharmacol 71: 1017-1028, 2019.

12. Hasaneen NA, Cao J, Pulkoski-Gross A, Zucker S and Foda HD: Extracellular matrix metalloproteinase inducer (EMMPRIN) promotes lung fibroblast proliferation, survival and differentiation to myofibroblasts. Respir Res 17: 17, 2016.

13. Sergew A and Brown KK: Advances in the treatment of idiopathic pulmonary fibrosis. Expert Opin Emerg Drugs 20: 537-552, 2015.

14. Liu B, Lü W, Ge H, Tang H, Li R and Zhang C: Protective effect of the traditional chinese patent medicine Qing-Xuan Granule against bleomycin-induced pulmonary fibrosis in mice. Chem Biodivers 16: e1900467, 2019.

15. Lin CC and Shieh DE: The anti-inflammatory activity of Scutellaria rivularis extracts and its active components, baicalin, baicalein and wogonin. Am J Chin Med 24: 31-36, 1996.

16. Gao Z, Huang K and Xu H: Protective effects of flavonoids in the roots of Scutellaria baicalensis georgi against hydrogen peroxide-induced oxidative stress in HS-SY5Y cells. Pharmacol Res 43: 173-178, 2001.

17. Huang Y, Tsang SY, Yao X and Chen ZY: Biological properties of baicalein in cardiovascular system. Curr Drug Targets Cardiovasc Haematol Disord 5: 177-184, 2005.

18. Wu X, Zhi F, Lun W, Deng Q and Zhang W: Baicalin inhibits PDGF-BB-induced hepatic stellate cell proliferation, apoptosis, invasion, migration and activation via the miR-3595/ACSL4 axis. Int J Mol Med 41: 1992-2002, 2018.

19. Huang S, Chen P, Shui X, He Y, Wang H, Zheng J, Zhang L, Li J, Xue Y, Chen C and Lei W: Baicalin attenuates transforming growth factor- $\beta 1$-induced human pulmonary artery smooth muscle cell proliferation and phenotypic switch by inhibiting hypoxia inducible factor- $1 \alpha$ and aryl hydrocarbon receptor expression. J Pharm Pharmacol 66: 1469-1477, 2014.

20. Cheng O, Li Z, Han Y, Jiang Q, Yan Y and Cheng K: Baicalin improved the spatial learning ability of global ischemia/reperfusion rats by reducing hippocampal apoptosis. Brain Res 1470: 111-118, 2012.

21. Orzechowska B, Chaber R, Wiśniewska A, Pajtasz-Piasecka E, Jatczak B, Siemieniec I, Gulanowski B, Chybicka A and Błach-Olszewska Z: Baicalin from the extract of Scutellaria baicalensis affects the innate immunity and apoptosis in leukocytes of children with acute lymphocytic leukemia. Int Immunopharmacol 23: 558-567, 2014

22. Wang P, Cao Y, Yu J, Liu R, Bai B, Qi H, Zhang Q, Guo W, Zhu $\mathrm{H}$ and Qu L: Baicalin alleviates ischemia-induced memory impairment by inhibiting the phosphorylation of CaMKII in hippocampus. Brain Res 1642: 95-103, 2016.

23. Wei XL, Fang RT, Yang YH, Bi XY, Ren GX, Luo AL, Zhao M and Zang WJ: Protective effects of extracts from Pomegranate peels and seeds on liver fibrosis induced by carbon tetrachloride in rats. BMC Complement Altern Med 15: 389, 2015.

24. Zheng L, Zhang C, Li L, Hu C, Hu M, Sidikejiang N, Wang X, Lin $M$ and Rong R: Baicalin ameliorates renal fibrosis via inhibition of transforming growth factor $\beta 1$ production and downstream signal transduction. Mol Med Rep 15: 1702-1712, 2017.

25. Liu T, Dai W, Li C, Liu F, Chen Y, Weng D and Chen J: Baicalin alleviates silica-induced lung inflammation and fibrosis by inhibiting the Th17 response in C57BL/6 mice. J Nat Prod 78: 3049-3057, 2015. 
26. Huang X,He Y, Chen Y,Wu P,Gui D, Cai H, Chen A, Chen M, Dai C, Yao D and Wang L: Baicalin attenuates bleomycin-induced pulmonary fibrosis via adenosine A2a receptor related TGF- $\beta 1$-induced ERK1/2 signaling pathway. BMC Pulm Med 16: 132, 2016.

27. Wu XL, Wang LK, Yang DD, Qu M, Yang YJ, Guo F, Han L and Xue J: Effects of Glut1 gene silencing on proliferation, differentiation, and apoptosis of colorectal cancer cells by targeting the TGF- $\beta$ /PI3K-AKT-mTOR signaling pathway. J Cell Biochem 119: 2356-2367, 2018.

28. Cantley LC: The phosphoinositide 3-kinase pathway. Science 296: 1655-1657, 2002.

29. Wang XQ, Sun $P$ and Paller AS: Inhibition of integrin-linked kinase/protein kinase B/Akt signaling: Mechanism for ganglioside-induced apoptosis. J Biol Chem 276: 44504-44511, 2001.

30. Li Y, Song YH, Mohler J and Delafontaine P: ANG II induces apoptosis of human vascular smooth muscle via extrinsic pathway involving inhibition of Akt phosphorylation and increased FasL expression. Am J Physiol Heart Circ Physiol 290: H2116-H2123, 2006.

31. Ma XM and Blenis J: Molecular mechanisms of mTOR-mediated translational control. Nat Rev Mol Cell Biol 10: 307-318, 2009.

32. Gui X, Chen H, Cai H, Sun L and Gu L: Leptin promotes pulmonary fibrosis development by inhibiting autophagy via PI3K/Akt/mTOR pathway. Biochem Biophys Res Commun 498: 660-666, 2018.

33. Tsoyi K, Chu SG, Patino-Jaramillo NG, Wilder J, Villalba J, Doyle-Eisele M, McDonald J, Liu X, El-Chemaly S, Perrella MA and Rosas IO: Syndecan-2 attenuates radiation-induced pulmonary fibrosis and inhibits fibroblast activation by regulating PI3K/Akt/ROCK pathway via CD148. Am J Respir Cell Mol Biol 58: 208-215, 2018.

34. Hsu HS, Liu CC, Lin JH, Hsu TW, Hsu JW, Su K and Hung SC: Involvement of ER stress, PI3K/AKT activation, and lung fibroblast proliferation in bleomycin-induced pulmonary fibrosis. Sci Rep 7: 14272, 2017.

35. Pitt GS: Calmodulin and CaMKII as molecular switches for cardiac ion channels. Cardiovasc Res 73: 641-647, 2007.

36. Mukherjee S, Sheng W, Sun R and Janssen LJ: $\mathrm{Ca}^{2+} /$ calmodulin-dependent protein kinase II $\beta$ and II $\delta$ mediate TGF $\beta$-induced transduction of fibronectin and collagen in human pulmonary fibroblasts. Am J Physiol Lung Cell Mol Physiol 312: L510-L519, 2017.

37. Williams CL, Phelps SH and Porter RA: Expression of $\mathrm{Ca}^{2+} /$ calmodulin-dependent protein kinase types II and IV, and reduced DNA synthesis due to the $\mathrm{Ca}^{2+} /$ calmodulin-dependent protein kinase inhibitor KN-62 (1-[N,O-bis(5-isoquinolinesulfo nyl)-N-methyl-L-tyrosyl]-4-phenyl piperazine) in small cell lung carcinoma. Biochem Pharmacol 51: 707-715, 1996.

38. Hwang YP, Kim HG, Hien TT, Jeong MH, Jeong TC and Jeong HG: Puerarin activates endothelial nitric oxide synthase through estrogen receptor-dependent PI3-kinase and calcium-dependent AMP-activated protein kinase. Toxicol Appl Pharmacol 257: 48-58, 2011.

39. Mukherjee S, Sheng W, Michkov A, Sriarm K, Sun R, Dvorkin-Gheva A, Insel PA and Janssen LJ: Prostaglandin E2 inhibits profibrotic function of human pulmonary fibroblasts by disrupting $\mathrm{Ca}^{2+}$ signaling. Am J Physiol Lung Cell Mol Physiol 316: L810-L821, 2019.

40. Monaco S, Illario M, Rusciano MR, Gragnaniello G, Di Spigna G, Leggiero E, Pastore L, Fenzi G, Rossi G and Vitale M: Insulin stimulates fibroblast proliferation through calcium-calmodulin-dependent kinase II. Cell Cycle 8: 2024-2030, 2009.

41. Choi EJ, Jin GY, Bok SM, Han YM, Lee YS, Jung MJ and Kwon KS: Serial micro-CT assessment of the therapeutic effects of rosiglitazone in a bleomycin-induced lung fibrosis mouse model. Korean J Radiol 15: 448-455, 2014.

42. Meng Y, Li T, Zhou GS, Chen Y, Yu CH, Pang MX, Li W, Li Y, Zhang WY and Li X: The angiotensin-converting enzyme 2/angiotensin (1-7)/Mas axis protects against lung fibroblast migration and lung fibrosis by inhibiting the NOX4-derived ROS-mediated RhoA/Rho kinase pathway. Antioxid Redox Signal 22: 241-258, 2015.

43. Zhang Q, Fan K, Wang P, Yu J, Liu R, Qi H, Sun H and Cao Y: Carvacrol induces the apoptosis of pulmonary artery smooth muscle cells under hypoxia. Eur J Pharmacol 770: 134-146, 2016.

44. Liu R, Zhang Q, Luo Q, Qiao H, Wang P, Yu J, Cao Y, Lu B and $\mathrm{Qu} \mathrm{L}$ : Norepinephrine stimulation of alpha1D-adrenoceptor promotes proliferation of pulmonary artery smooth muscle cells via ERK-1/2 signaling. Int J Biochem Cell Biol 88: 100-112, 2017.
45. Wang P, Luo Q, Qiao H, Ding H, Cao Y, Yu J, Liu R, Zhang Q, Zhu H and Qu L: The neuroprotective effects of carvacrol on ethanol-induced hippocampal neurons impairment via the antioxidative and antiapoptotic pathways. Oxid Med Cell Longev 2017: 4079425, 2017.

46. Li L, Cai L, Zheng L, Hu Y, Yuan W, Guo Z and Li W: Gefitinib inhibits bleomycin-induced pulmonary fibrosis via alleviating the oxidative damage in mice. Oxid Med Cell Longev 2018: 8249693, 2018

47. Cory S, Huang DC and Adams JM: The Bcl-2 family: Roles in cell survival and oncogenesis. Oncogene 22: 8590-8607, 2003.

48. Chen M, Guerrero AD, Huang L, Shabier Z, Pan M, Tan TH and Wang J: Caspase-9-induced mitochondrial disruption through cleavage of anti-apoptotic BCL-2 family members. J Biol Chem 282: 33888-33895, 2007.

49. Noble PW, Barkauskas CE and Jiang D: Pulmonary fibrosis: Patterns and perpetrators. J Clin Invest 122: 2756-2762, 2012

50. Moeller A, Ask K, Warburton D, Gauldie J and Kolb M: The bleomycin animal model: A useful tool to investigate treatment options for idiopathic pulmonary fibrosis? Int J Biochem Cell Biol 40: 362-382, 2008.

51. Gao C, Zhou Y, Li H, Cong X, Jiang Z, Wang X, Cao R and Tian W: Antitumor effects of baicalin on ovarian cancer cells through induction of cell apoptosis and inhibition of cell migration in vitro. Mol Med Rep 16: 8729-8734, 2017.

52. Li X, Zou K, Gou J, Du Q, Li D, He X and Li Z: Effect of baicalin-copper on the induction of apoptosis in human hepatoblastoma cancer HepG2 cells. Med Oncol 32: 72, 2015.

53. Ren X, Zhang Z, Tian J, Wang H, Song G, Guo Q, Tian J, Han Y, Liao Q, Liu G, et al: The downregulation of c-Myc and its target gene hTERT is associated with the antiproliferative effects of baicalin on HL-60 cells. Oncol Lett 14: 6833-6840, 2017.

54. Mouratis MA and Aidinis V: Modeling pulmonary fibrosis with bleomycin. Curr Opin Pulm Med 17: 355-361, 2011.

55. Chen C, Wang YY, Wang YX, Cheng MQ, Yin JB, Zhang X and Hong ZP: Gentiopicroside ameliorates bleomycin-induced pulmonary fibrosis in mice via inhibiting inflammatory and fibrotic process. Biochem Biophys Res Commun 495: 2396-2403, 2018.

56. Ji YD, Luo ZL, Chen CX, Li B, Gong J, Wang YX, Chen L, Yao SL and Shang Y: BML-111 suppresses TGF- $\beta 1$-induced lung fibroblast activation in vitro and decreases experimental pulmonary fibrosis in vivo. Int J Mol Med 42: 3083-3092, 2018.

57. Huang C, Wu X, Wang S, Wang W, Guo F, Chen Y, Pan B, Zhang $M$ and Fan $X$ : Combination of Salvia miltiorrhiza and ligustrazine attenuates bleomycin-induced pulmonary fibrosis in rats via modulating TNF- $\alpha$ and TGF- $\beta$. Chin Med 13: 36, 2018.

58. Jin M, Wang L, Wu Y, Zang BX and Tan L: Protective effect of hydroxysafflor yellow A on bleomycin-induced pulmonary inflammation and fibrosis in rats. Chin J Integr Med 24: 32-39, 2018.

59. Akter T, Silver RM and Bogatkevich GS: Recent advances in understanding the pathogenesis of scleroderma-interstitial lung disease. Curr Rheumatol Rep 16: 411, 2014.

60. Schoenfeld SR and Castelino FV: Interstitial lung disease in scleroderma. Rheum Dis Clin North Am 41: 237-248, 2015.

61. Lu Q, Guo Z, Xie W, Jin W, Zhu D, Chen S and Ren T: The lncRNA H19 mediates pulmonary fibrosis by regulating the miR-196a/COL1A1 axis. Inflammation 41: 896-903, 2018.

62. Honda H, Fujimoto M, Serada S, Urushima H, Mishima T, Lee H, Ohkawara T, Kohno N, Hattori N, Yokoyama A and Naka T: Leucine-rich $\alpha-2$ glycoprotein promotes lung fibrosis by modulating TGF- $\beta$ signaling in fibroblasts. Physiol Rep 5: e13556, 2017.

63. Todd NW, Luzina IG and Atamas SP: Molecular and cellular mechanisms of pulmonary fibrosis. Fibrogenesis Tissue Repair 5 : $11,2012$.

64. Inghilleri S, Morbini P, Oggionni T, Barni S and Fenoglio C: In situ assessment of oxidant and nitrogenic stress in bleomycin pulmonary fibrosis. Histochem Cell Biol 125: 661-669, 2006.

65. Kinnula VL and Myllärniemi M: Oxidant-antioxidant imbalance as a potential contributor to the progression of human pulmonary fibrosis. Antioxid Redox Signal 10: 727-738, 2008.

66. Fubini B and Hubbard A: Reactive oxygen species (ROS) and reactive nitrogen species (RNS) generation by silica in inflammation and fibrosis. Free Radic Biol Med 34: 1507-1516, 2003.

67. Gao F, Kinnula VL, Myllärniemi M and Oury TD: Extracellular superoxide dismutase in pulmonary fibrosis. Antioxid Redox Signal 10: 343-354, 2008.

68. Lin $\mathrm{CH}$, Shih $\mathrm{CH}$, Lin YC, Yang YL and Chen BC: MEKK1, JNK, and SMAD3 mediate CXCL12-stimulated connective tissue growth factor expression in human lung fibroblasts. J Biomed Sci 25: 19, 2018. 
69. Arezzini B, Vecchio D, Signorini C, Stringa B and Gardi C: F2-isoprostanes can mediate bleomycin-induced lung fibrosis. Free Radic Biol Med 115: 1-9, 2018.

70. Tian R, Zhu Y, Yao J, Meng X, Wang J, Xie H and Wang R: NLRP3 participates in the regulation of EMT in bleomycin-induced pulmonary fibrosis. Exp Cell Res 357: 328-334, 2017.

71. Chen X, Nishida $H$ and Konishi T: Baicalin promoted the repair of DNA single strand breakage caused by $\mathrm{H} 2 \mathrm{O} 2$ in cultured NIH3T3 fibroblasts. Biol Pharm Bull 26: 282-284, 2003.

72. Jiang H, Lv P, Li J, Wang H, Zhou T, Liu Y and Lin W: Baicalin inhibits colistin sulfate-induced apoptosis of PC12 cells. Neural Regen Res 8: 2597-2604, 2013.

73. Chen WC, Kuo TH, Tzeng YS and Tsai YC: Baicalin induces apoptosis in SW620 human colorectal carcinoma cells in vitro and suppresses tumor growth in vivo. Molecules 17: 3844-3857, 2012.

74. Zhang Q, Cao Y, Luo Q, Wang P, Shi P, Song C, E M, Ren J, Fu B and Sun H: The transient receptor potential vanilloid-3 regulates hypoxia-mediated pulmonary artery smooth muscle cells proliferation via PI3K/AKT signaling pathway. Cell Prolif 51: e12436, 2018.

75. Ding L, Huang Y, Dai M, Zhao X, Du Q, Dong F, Wang L, Huo R, Zhang W, Xu X and Tong D: Transmissible gastroenteritis virus infection induces cell cycle arrest at $\mathrm{S}$ and $\mathrm{G} 2 / \mathrm{M}$ phases via p53-dependent pathway. Virus Res 178: 241-251, 2013.

76. Zhong C, Han Y, Ma J, Zhang X, Sun M, Wang Y, Chen J, Mi W, Xu X and Qiu J: Viral-mediated expression of c-Myc and cyclin A2 induces cochlear progenitor cell proliferation. Neurosci Lett 591: 93-98, 2015.

77. Joshaghani HR, Jafari SM, Aghaei M, Panjehpour M and Abedi H A3 adenosine receptor agonist induce G1 cell cycle arrest via Cyclin D and cyclin-dependent kinase 4 pathways in OVCAR-3 and Caov-4 cell lines. J Cancer Res Ther 13: 107-112, 2017.

78. Ventura C, Núñez M, Gaido V, Pontillo C, Miret N, Randi A and Cocca $\mathrm{C}$ : Hexachlorobenzene alters cell cycle by regulating p27-cyclin E-CDK2 and c-Src-p27 protein complexes. Toxicol Lett 270: 72-79, 2017

79. Lu Y, Azad N, Wang L, Iyer AK, Castranova V, Jiang BH and Rojanasakul Y: Phosphatidylinositol-3-kinase/akt regulates bleomycin-induced fibroblast proliferation and collagen production. Am J Respir Cell Mol Biol 42: 432-441, 2010.

80. Ma SY, Park WS, Lee DS, Choi G, Yim MJ, Lee JM, Jung WK, Park SG, Seo SK, Park SJ, et al: Fucoxanthin inhibits profibrotic protein expression in vitro and attenuates bleomycin-induced lung fibrosis in vivo. Eur J Pharmacol 811: 199-207, 2017.

81. Zhang YP, Li WB, Wang WL, Liu J, Song SX, Bai LL, Hu YY, Yuan YD and Zhang M: siRNA against plasminogen activator inhibitor-1 ameliorates bleomycin-induced lung fibrosis in rats. Acta Pharmacol Sin 33: 897-908, 2012.
82. Wu X, Li J, Yang X, Bai X, Shi J, Gao J, Li Y, Han S, Zhang Y, Han F, et al: miR-155 inhibits the formation of hypertrophic scar fibroblasts by targeting HIF-1 $\alpha$ via PI3K/AKT pathway. J Mol Histol 49: 377-387, 2018.

83. Phosri S, Arieyawong A, Bunrukchai K, Parichatikanond W, Nishimura A, Nishida $M$ and Mangmool S: Stimulation of adenosine $A_{2 B}$ receptor inhibits endothelin-1-induced cardiac fibroblast proliferation and $\alpha$-smooth muscle actin synthesis through the cAMP/Epac/PI3K/Akt-signaling pathway. Front Pharmacol 8: 428, 2017.

84. Yuan J, Li P, Pan H, Li Y, Xu Q, Xu T, Ji X, Liu Y, Yao W, Han L and Ni C: miR-542-5p attenuates fibroblast activation by targeting integrin $\alpha 6$ in silica-induced pulmonary fibrosis. Int $\mathrm{J}$ Mol Sci 19: E3717, 2018.

85. He Z, Deng Y, Li W, Chen Y, Xing S, Zhao X, Ding J, Gao Y and Wang X: Overexpression of PTEN suppresses lipopolysaccharide-induced lung fibroblast proliferation, differentiation and collagen secretion through inhibition of the PI3-K-Akt-GSK3beta pathway. Cell Biosci 4: 2, 2014

86. Hurley RL, Anderson KA, Franzone JM, Kemp BE, Means AR and Witters LA: The Ca2+/calmodulin-dependent protein kinase kinases are AMP-activated protein kinase kinases. J Biol Chem 280: 29060-29066, 2005.

87. Woods A, Dickerson K, Heath R, Hong SP, Momcilovic M, Johnstone SR, Carlson $M$ and Carling D: Ca2+/calmodulin-dependent protein kinase kinase-beta acts upstream of AMP-activated protein kinase in mammalian cells. Cell Metab 2: 21-33, 2005

88. Imoto K, Okada $\mathrm{M}$ and Yamawaki H: Characterization of fibroblasts from hypertrophied right ventricle of pulmonary hypertensive rats. Pflugers Arch 470: 1405-1417, 2018.

89. Sazonova OV, Blishchenko EY, Tolmazova AG, Khachin DP, Leontiev KV, Karelin AA and Ivanov VT: Stimulation of fibroblast proliferation by neokyotorphin requires $\mathrm{Ca}$ influx and activation of PKA, CaMK II and MAPK/ERK. FEBS J 274: 474-484, 2007.

(i) $(-)$ This work is licensed under a Creative Commons Attribution-NonCommercial-NoDerivatives 4.0 International (CC BY-NC-ND 4.0) License. 